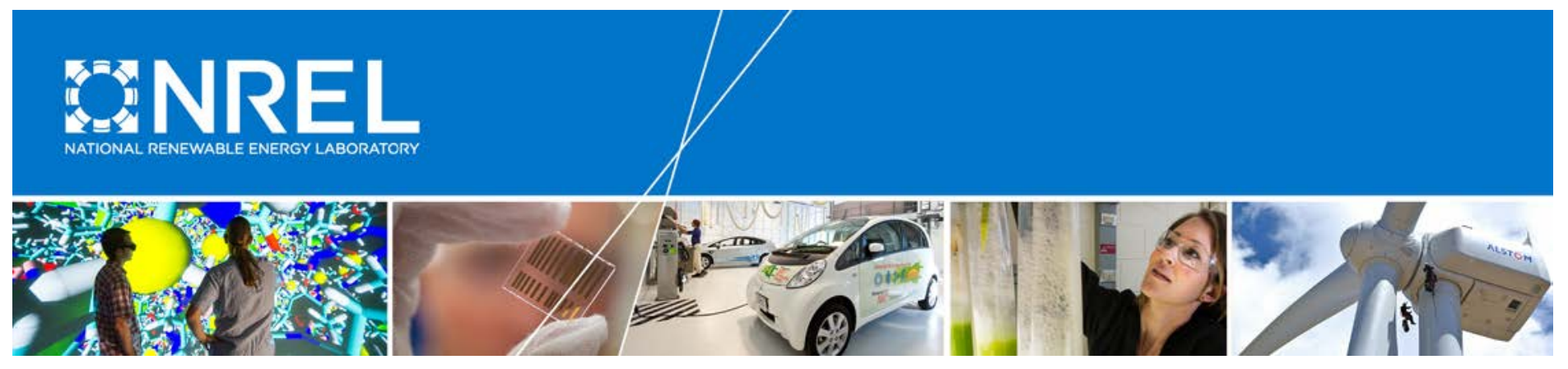

\title{
Sustainable Energy for Remote Indonesian Grids: Strategies to Accelerate Nationwide Deployment
}

Tim Reber and Kari Burman

National Renewable Energy Laboratory

Brian Hirsch

Deerstone Consulting, LLC

Produced under direction of the Department of Energy by the National Renewable Energy Laboratory (NREL) under DE-FOA-0000620 -

Accelerating the Deployment of Energy Efficiency and Renewable Energy in Indonesia (Task No.7: Evaluation and National Replication)

NREL is a national laboratory of the U.S. Department of Energy Office of Energy Efficiency \& Renewable Energy Operated by the Alliance for Sustainable Energy, LLC

This report is available at no cost from the National Renewable Energy Laboratory (NREL) at www.nrel.gov/publications.

Technical Report

NREL/TP-7A40-66548

December 2016

Contract No. DE-AC36-08G028308 


\section{Sustainable Energy for Remote Indonesian Grids: Strategies to Accelerate Nationwide Deployment}

Tim Reber and Kari Burman

National Renewable Energy Laboratory

Brian Hirsch

Deerstone Consulting, LLC

Prepared under Task No. IGIN6200
NREL is a national laboratory of the U.S. Department of Energy Office of Energy Efficiency \& Renewable Energy Operated by the Alliance for Sustainable Energy, LLC

This report is available at no cost from the National Renewable Energy Laboratory (NREL) at www.nrel.gov/publications.

\section{Technical Report}

NREL/TP-7A40-66548

December 2016

Contract No. DE-AC36-08G028308
National Renewable Energy Laboratory 15013 Denver West Parkway

Golden, CO 80401

303-275-3000 • www.nrel.gov 


\section{NOTICE}

This manuscript has been authored by employees of the Alliance for Sustainable Energy, LLC ("Alliance") under Contract No. DE-AC36-08GO28308 with the U.S. Department of Energy ("DOE”).

This report was prepared as an account of work sponsored by an agency of the United States government. Neither the United States government nor any agency thereof, nor any of their employees, makes any warranty, express or implied, or assumes any legal liability or responsibility for the accuracy, completeness, or usefulness of any information, apparatus, product, or process disclosed, or represents that its use would not infringe privately owned rights. Reference herein to any specific commercial product, process, or service by trade name, trademark, manufacturer, or otherwise does not necessarily constitute or imply its endorsement, recommendation, or favoring by the United States government or any agency thereof. The views and opinions of authors expressed herein do not necessarily state or reflect those of the United States government or any agency thereof. 


\section{Acknowledgments}

NREL thanks Winrock International for its support and input throughout the entirety of the Sustainable Energy for Remote Indonesian Grids (SERIG) project. NREL would like to thank the Government of Indonesia, Kementarian Energi dan Sumber Daya Mineral (ESDM) and its Directorate General for Energi Baru Terbarukan dan Konservasi Energi (EBTKE), and Perusahaan Listrik Negara (PLN), for their insight and assistance during the project, as well as Program Indonesia Terang (PIT). Several government agencies and individuals in Lamandau, Sabu Island, and Sumba Island were invaluable for their assistance during the SERIG team site visits. Multiple other groups and organizations provided insight, assistance and support during development of this report, including the U.S. Power Working Group for Indonesia (PWG), the U.S. Foreign Commercial Service (FCS), the U.S. Department of State, the U.S. Agency for International Development (USAID)and its Indonesia Clean Energy Development (ICED) project, the Danish International Development Agency (DANIDA), and Sewatama Power. 


\section{List of Abbreviations and Acronyms}

\begin{tabular}{|c|c|}
\hline \multirow{3}{*}{$\begin{array}{l}\text { ADB } \\
\text { APBN }\end{array}$} & Asian Development Bank \\
\hline & Anggaran Pendapatan dan Belanja Negara \\
\hline & (State Budget, Income and Expenditure) \\
\hline \multirow[t]{2}{*}{ BAPPENAS } & Badan Perencanaan Pembangunan Nasional \\
\hline & (National Development Planning Agency) \\
\hline \multirow[t]{2}{*}{ BPPT } & Badan Pengkajian dan Penerapan Teknologi \\
\hline & (Agency for Assessment and Application of Technology) \\
\hline CESC & Clean Energy Solutions Center \\
\hline DANIDA & Danish International Development Agency \\
\hline DOE & U.S. Department of Energy \\
\hline \multirow[t]{2}{*}{ EBTKE } & (Direktorat Jenderal) Energi Baru Terbarukan dan Konservasi Energi \\
\hline & (Directorate General of Renewable Energy and Energy Conservation) \\
\hline $\mathrm{EE}$ & energy efficiency \\
\hline ESDM & $\begin{array}{l}\text { Kementarian Energi dan Sumber daya Mineral } \\
\text { (Ministry of Energy and Mineral Resources) }\end{array}$ \\
\hline FiT & feed-in tariff \\
\hline GOI & Government of Indonesia \\
\hline GW & gigawatt \\
\hline HOMER & hybrid optimization for multiple energy resources \\
\hline IDR & Indonesian rupiah \\
\hline IPP & independent power producer \\
\hline $\mathrm{kW}$ & kilowatt \\
\hline $\mathrm{kWh}$ & kilowatt-hour \\
\hline $\mathrm{LCOE}$ & levelized cost of energy \\
\hline LED & light-emitting diode \\
\hline $\mathrm{MoF}$ & Ministry of Finance \\
\hline MW & megawatt \\
\hline MWe & megawatt electric \\
\hline $\mathrm{NGO}$ & non-governmental organization \\
\hline NRE & new and renewable energy \\
\hline NREL & National Renewable Energy Laboratory \\
\hline NTT & Nusa Tenggara Timor (East Nusa Tengarra province) \\
\hline O\&M & operations and maintenance \\
\hline PLN & Perusahaan Listrik Negara (State Electricity Company) \\
\hline POME & palm oil mill effluent \\
\hline PPA & power purchase agreement \\
\hline PT & Perseroan Terbatas (Limited Company) \\
\hline PV & photovoltaics \\
\hline $\mathrm{RE}$ & renewable energy \\
\hline RUPTL & Rencana Usaha Penyediaan Tenaga Listrik (Electrical Power Supply Business Plan) \\
\hline SERIG & Sustainable Energy for Remote Indonesian Grids \\
\hline SII & Sumba Iconic Island \\
\hline WI & Winrock International \\
\hline
\end{tabular}




\section{Executive Summary}

Indonesia is a large, rapidly-growing nation with outstanding natural resources and a rising appetite for energy to fuel its booming economic development. Consuming an estimated 6.2 quadrillion BTU per year, Indonesia has historically been heavily reliant on petroleum, coal and gas to meet its growing energy needs and fuel its $50 \mathrm{GW}$ of installed power capacity. To help meet growing demand, the administration of President Joko Widodo announced plans to add $35 \mathrm{GW}$ of new generation over five years through 2019 - with $25 \%$ of that new generation to come from new and renewable (NRE) energy sources.

Compounding the challenge of meeting growing demand while increasing use of NRE, is the challenge of transmitting and distributing power. While the majority of Indonesia's 250 million people are concentrated on the two main islands of Java and Sumatra, the rest are spread across some 1,000 permanently inhabited islands. The size and extent of these island populations can make power transmission challenging, resulting in an estimated 900 isolated grids across the country-most powered by inefficient diesel generators.

To help address some of these challenges, the Sustainable Energy for Remote Indonesian Grids (SERIG) project aims to support accelerated deployment of renewable energy (RE) in small, remote grids in Indonesia. Funded by the U.S. Department of Energy (DOE) and implemented by the U.S. National Renewable Energy Laboratory (NREL) and Winrock International (WI), the SERIG initiative is providing techno-economic analysis to support business cases for RE deployment, stakeholder outreach and engagement to build support for the transition, and strategies for encouraging private-sector engagement and accelerating deployment of RE in remote grids nationwide.

The first phase of the SERIG project involved a detailed site selection process and techno-economic analysis. Starting with the 900 isolated diesel grids across Indonesia, SERIG selected 3 on which to perform a detailed evaluation of RE options and economic pre-feasibility studies. Hybrid systems of solar and wind with diesel, as well as pure biomass options are put forward as viable options for development and serve as example studies for business-case validation. A June 2015 report published by NREL, Sustainable Energy for Remote Indonesian Grids: Accelerating Project Development, (Hirsch et al. 2015) describes these analyses in great detail.

The second phase of SERIG - embodied in this report - suggests strategies that can help facilitate wide-spread deployment of renewable energy in remote grids across Indonesia. Drawing upon SERIG's prior in-country experience, discussions with key public and private Indonesian stakeholders, and NREL's wealth of experience from other countries, this report provides a strategic, high-level framework for accelerating widespread RE deployment in remote grids. Importantly, it suggests near-term execution pathways specific to Indonesia-given the nation's existing policy and project development landscape - that could help increase RE use across the nation's hundreds of isolated grids. The execution pathways are targeted at Government of Indonesia decision-makers and stakeholders. Key strategic elements of the framework and execution pathways for Indonesia comprise the primary discussion in this report, and are summarized in Figure ES-1. A summary of the execution pathways for Indonesia follows the figure. 
Strategic Elements

Establish Goals and

Coordinate Actors

Engage and Develop Market

Participants

\section{Execution Pathways for Indonesia}

- Strengthen coordination among relevant ministries and task forces

- Provide a resource hub for knowledge, assistance and outreach

- Perform nationwide opportunity assessments

- Provide standardized guidance for feasibility studies

Provide Local Proof of Concept

- Invest in a few, high-quality demonstrations and work through problems

- Strengthen and clarify the regulatory framework

- Benchmark remote tariffs to local fuel costs

- Bundle projects for development

- Financially back remote projects where appropriate

- Support business models tailored to community circumstances
Enable Flexible, Innovative

Business Models
Facilitate Favorable Market

Channel Finance to Remote Projects

Figure ES-1. Elements of a nationwide deployment strategy, with suggested execution pathways for Indonesia

Establishing national goals and coordinating the actors responsible for implementing them is the foundation upon which any national-level strategy must be based, and Indonesia has made strides in this area by setting goals of $25 \%$ renewable energy by 2025 and near-universal electrification by 2020. Still, the work is only beginning and there are actions that can be taken to help accelerate the pace, such as strengthening coordination among relevant ministries and actors_-perhaps through an established inter-ministry task force explicitly responsible for coordination.

Provision of proof of concept at the local scale is a critical early step and can tie directly into efforts to engage and develop stakeholders. Demonstration sites can serve as a valuable learning tool to help develop a trained workforce while bolstering faith in the ability of new technology to deliver. However, demonstration sites are only effective so long as the effort is sustained to keep them working and solve challenges as they arise, hence the critical importance of investing in highquality demonstration sites and working through problems. The three SERIG pilot sites could serve as such educational demonstration sites representing different technologies and different regions.

To maximize the impact of demonstration sites, a centralized resource hub for remote renewable energy knowledge, assistance and outreach can serve as a key focal point to coordinate demonstration efforts and facilitate workshops and trainings aimed at building a workforce and educating stakeholders. Such a hub could also assist developers with relevant guidance on remote 
energy regulations and important procedures, and even help connect developers with appropriate sources of finance by serving as a financial intermediary.

While demonstration and stakeholder development efforts are underway, parallel efforts can be made to assess and identify opportunities for remote renewable energy development. A nationwide opportunity assessment incorporating resource, infrastructure, consumption and cost data can serve as a first pass to identify remote locations worthy of further investigation. Providing standardized guidance on feasibility studies can help ensure that those responsible for more detailed, site-specific follow-up investigations are doing a thorough and accurate job and only recommending sites that are truly bankable.

Once remote renewable energy concepts are proven, stakeholders are engaged and supportive, and the best opportunities are identified, the next step is to hand the process off to developers. Before this can be done, however, the investment climate must be right and certain regulations and safeguards must be in place. Efforts to strengthen and clarify the regulatory framework in regards to remote renewable energy, such as revising interconnection rules and domestic content requirements, can provide much-needed certainty and ease investor fears. At the same time, technology-agnostic feed-in-tariffs proportionally benchmarked to the local cost of dieselrather than to nationwide average costs of specific renewable energy technologies - can simplify the tariff structure and help selectively guide developers to those remote locations that currently operate at the highest monetary loss.

Bundling remote projects of similar scope or geography can boost economies of scale and help attract large investors who may otherwise ignore such small and remote projects. In some cases, it may be appropriate for the government to financially back remote renewable energy projects through mechanisms such as loan guarantees or by adjusting national budget priorities. Ultimately, though, widespread deployment will hinge on the ability of private enterprises and government to support innovative new business models tailored to community circumstances across the nation.

These strategies alone, however, will not induce change. Only committed and resolute action will transform the concepts here into tangible new energy infrastructure that will bring clean, reliable power to all of Indonesia's 250 million people and meet the nation's ambitious - yet achievablegoals. With such a vast diversity of resources and a wealth of human capacity at hand, Indonesia is poised to take its place as one of the world's foremost clean energy leaders. 


\section{Table of Contents}

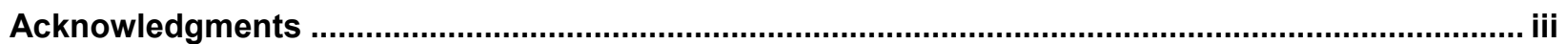

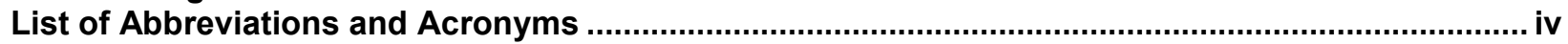

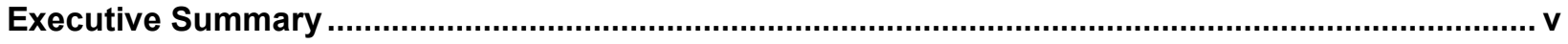

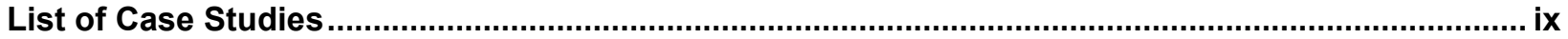

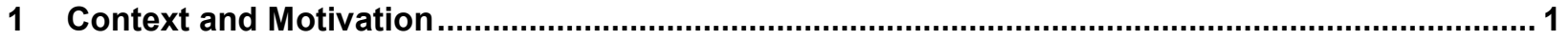

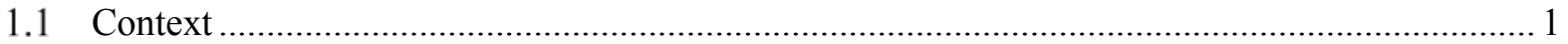

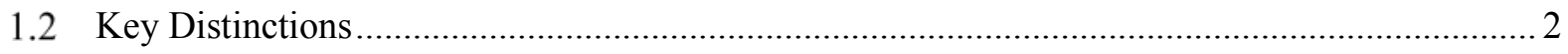

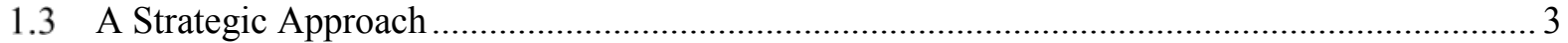

2 Current Renewable Energy and Rural Electrification Landscape in Indonesia ........................... 4

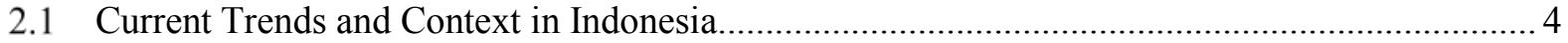

2.2 Current Project Development Landscape in Indonesia .................................................... 5

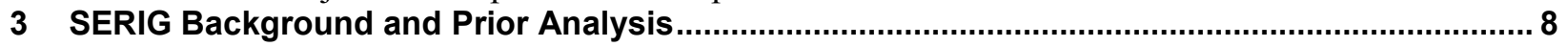

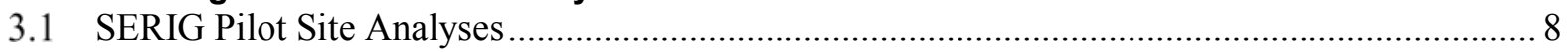

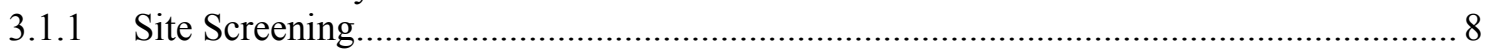

3.1.2 Techno-Economic Evaluation ..................................................................... 8

3.2 SERIG Pilot Project Summaries............................................................................ 9

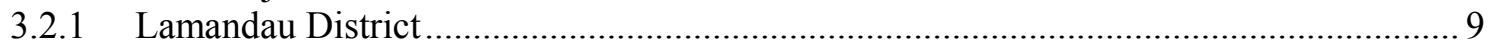

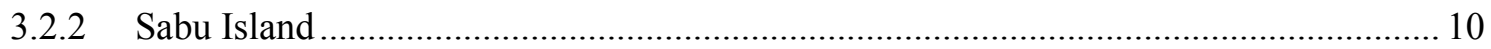

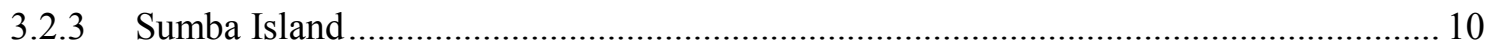

4 Strategies to Accelerate Nationwide Deployment of Sustainable Energy in Remote Grids ..... 10

4.1 Establish Goals and Coordinate Actors............................................................................ 12

4.1.1 Execution Pathway for Indonesia: Strengthen Coordination Among Relevant Ministries

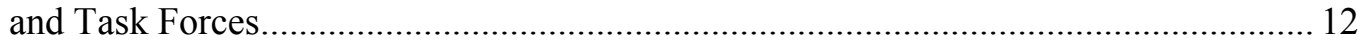

4.2 Engage and Develop Market Participants ....................................................................... 14

4.2.1 Execution Pathway for Indonesia: Provide a Resource Hub for Knowledge, Assistance,

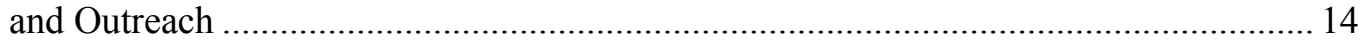

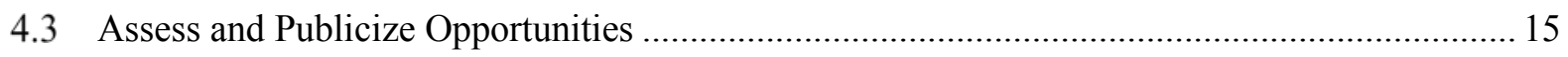

4.3.1 Execution Pathway for Indonesia: Perform Nationwide Opportunity Assessments ...... 16

4.3.2 Execution Pathway for Indonesia: Provide Standardized Guidance for Feasibility

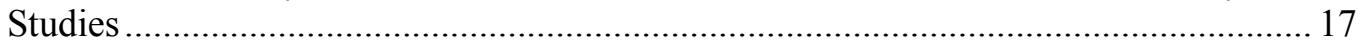

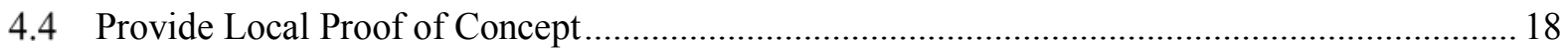

4.4.1 Execution Pathway for Indonesia: Invest in a Few, High-Quality Demonstrations and

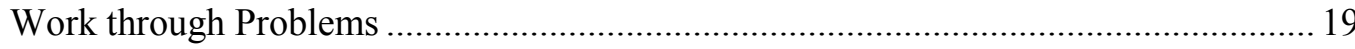

4.5 Facilitate Favorable Market Conditions for Renewable Energy …........................................... 20

4.5.1 Execution Pathway for Indonesia: Strengthen and Clarify the Regulatory Framework 21

4.5.2 Execution Pathway for Indonesia: Benchmark Remote Tariffs to Local Fuel Costs..... 22

4.6 Channel Finance to Remote Projects...................................................................................... 23

4.6.1 Execution Pathway for Indonesia: Bundle Projects for Development .......................... 24

4.6.2 Execution Pathway for Indonesia: Financially Back Remote Projects where

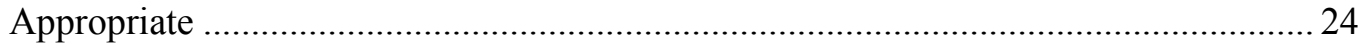

4.7 Enable Flexible, Innovative Business Models ................................................................... 25

4.7.1 Execution Pathway for Indonesia: Support Business Models Tailored to Community

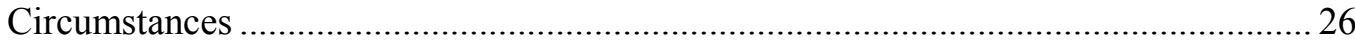

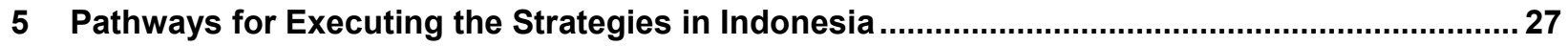

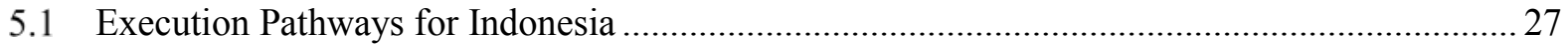

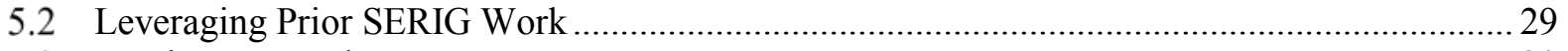

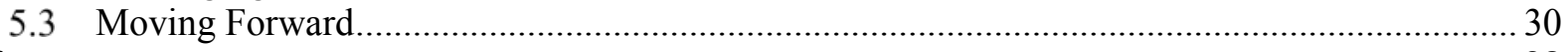

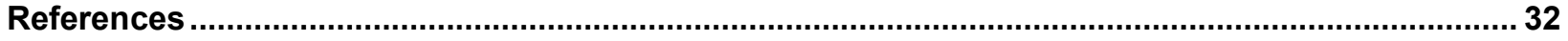




\section{List of Case Studies}

Case Study 1. Hawaii Clean Energy Initiative Sets 70\% Renewable Energy Goal by 2030 ................... 12

Case Study 2. Pacific Territories Establish Energy Task Forces ............................................................ 13

Case Study 3. Alaska Builds Indigenous Capacity to Install and Maintain Wind-Diesel Systems ............ 14

Case Study 4. CIRCLE Assesses Biogas Opportunity....................................................................... 16

Case Study 5. Solar PV Demonstration on Lanai, Hawaii Paves Way for Further Developments ............ 19

Case Study 6. Sumba Iconic Island Initiative Aims to Provide Demonstration ......................................... 19

Case Study 7: Mali Encourages Private-Sector Mini-grid Development ............................................... 26 


\section{Context and Motivation}

Sustainable Energy for Remote Indonesian Grids (SERIG) is a United States Department of Energy (DOE)-funded initiative to support Indonesia's efforts to develop clean energy and increase access to electricity in remote locations. The project is comprised of two phases. SERIG first conducted bottoms-up site screening and techno-economic analysis for high-penetration renewable energy (RE) at select locations. The second phase - embodied in this report - now aims to offer strategies that could help the Government of Indonesia accelerate widespread deployment of renewable energy in remote grids, given the existing remote RE policy and project development landscape in Indonesia.

\subsection{Context}

Indonesia is a large, rapidly growing nation with tremendous natural resources and an everexpanding appetite for all forms of energy. Petroleum has been the main source of energy for the country for decades, followed by coal and gas. Currently Indonesia relies on petroleum to meet $41 \%$ of its 6.2 quadrillion BTU annual energy demand, followed by coal (30\%), gas (23\%), and renewable energy $(6 \%)$. However, the nation's reserves of petroleum, gas, and coal are expected to run out within the next 10,30 and 80 years, respectively. Indonesia's energy consumption grew an astounding 44\% between 2002 and 2012, feeding an economy that has been steadily growing at 5$6 \%$ annually for over a decade. This increased energy demand has led to acute energy shortages, resulting in Indonesia's shift from being a net petroleum exporter to importer in 2004. Developing alternative sources of renewable energy is seen as one of the best long-term solutions to fill the gap caused by rapidly increasing energy demand and reduced domestic fossil fuel supplies.

To meet growing energy demand and fuel economic development, the administration of President Joko Widodo announced a plan for development of $35 \mathrm{GW}$ of new generation assets over five years through 2019-including both fossil and renewable sources, with an emphasis on large population centers and centralized generation plants. The national goal calls for $25 \%$ of the new $35 \mathrm{GW}$ to come from renewable energy, with an overall goal of reaching $25 \%$ renewables in Indonesia's energy mix by 2025 . The Government of Indonesia has also set the goal of achieving near-universal electrification by 2020 (84\% of the population had access to electricity as of 2014) (ESDM 2014) Meeting these goals will require significant investment from the Government of Indonesia, including the state-owned utility (PLN) and the Ministry of Energy and Mineral Resources (ESDM), multilateral banks and other financiers, and the private sector. Further, effective planning and policymaking, stakeholder outreach and coordination, human capacity building, resource and technology assessment and deployment, and other initiatives must be fully articulated and accelerated to meet such ambitious goals.

This report, like previous activities under SERIG, aims to contribute to this momentum. Building toward a nationwide deployment strategy, this effort embodies substantial research and input from public and private sector leaders and experts, including government ministries, project developers, technology providers, financiers, and international donors, to offer a framework, concrete examples, and suggestions for broad clean energy expansion. Yet Indonesia's unique physical and institutional structures - namely $17,000+$ islands spread across $5,000 \mathrm{~km}$ of the equator, thousands of diverse languages and cultures receiving electrical service primarily from a single national utility, and various central Ministries issuing policies and allocating resources to distinctly unique and highly 
influential local governments and Kabupaten ${ }^{1}$ — make a tidy, comprehensive development roadmap difficult to construct.

\subsection{Key Distinctions}

In crafting an approach to sustainable energy development, it is important to clarify certain terms and unique attributes of the challenges and opportunities. In particular for this discussion, "remote grids" refers to locations that typically rely on diesel-fueled generation for baseload power in relatively small capacities (e.g. less than 10MW). The reason for this focus is the high cost of diesel fuel — which makes renewables more appealing — and the unique technical challenges associated with integrating large amounts of intermittent renewables such as wind and solar into diesel-based grids. Within Indonesia this generally implies a geographic focus exclusive of the large Java-Bali inter-connected grid, which is primarily coal-fired. Yet even within that grid, Bali has approximately $500 \mathrm{MW}$ of diesel-generated electricity and in some parts of Java there remain whole communitiesand millions of people - currently not connected to reliable grid power. For more information see GOI \& ADB (2015) for an excellent overview of electricity access challenges and policy options in Indonesia

The terms "sustainable energy" and "clean energy" as used here include both renewable energy generation and energy efficiency. The focus, however, is on renewable energy generation. On the matter of energy efficiency, two previous SERIG analyses examined EE opportunities from both the end-user perspective and the supply perspective (i.e., increased diesel generation and distribution efficiency). ${ }^{2}$ An important outcome of this analysis was that the largest energy efficiency opportunities in remote grids are not on the user or demand side, but rather on the generation and distribution side. In remote locations, electrical energy is often a precious and scarce commodity with little waste by individual users. However, many of the diesel generators used in remote locations are quite old and inefficient, and not easily capable of integrating large amounts of renewable energy that rapidly fluctuates as sun or wind availability changes. More modern, efficient generators capable of quickly ramping up or down to better match variable system loads can improve diesel generation performance as much as $15 \%$ or $20 \%$ and prepare the system for integration of variable RE. In general, it is widely accepted that a least-cost clean energy plan should start with reducing demand and maximizing use of existing generation via a robust energy efficiency program before new generation is developed.

From the renewable energy generation side, the focus here is primarily on intermittent renewables that pose unique integration challenges for diesel-based power (i.e., wind and solar PV). Wind and solar resources are globally the fastest growing renewables, yet their high variability poses specific technical, economic, and policy challenges to accelerate their development. Within Indonesia, other renewables - namely hydro, geothermal, and biomass - are relatively more established and understood. Though challenges for these resources remain, they can typically provide at least seasonal baseload power and have been deployed more successfully across the country. Still, these resources must be included in any broad discussion of clean energy development.

\footnotetext{
${ }^{1}$ A Kabupaten is a sub-provincial administrative division with (typically) a high degree of influence and local authority.
}

${ }^{2}$ These studies have not been published. Please contact the authors of this report if you are interested in obtaining these. 
As the SERIG name implies, this clean energy deployment strategy emphasizes "on-grid" solutions, as compared to "off-grid." It should be noted, however, that the distinction between on-grid and offgrid is often more a matter of degree than a firm division. This is especially true in Indonesia, where numerous small- and medium-sized isolated grids exist across hundreds of islands, often operating right alongside stand-alone household- or community-sized power facilities. In general the recommendations and best practices identified here may apply to both situations, though currently different policies and institutions, such as PLN and ESDM, within the Indonesian energy sector often play different roles in on-grid versus off-grid applications. Technology solutions may differ as well. Off-grid power such as rooftop or community-based solar PV, for example, may be the cheapest and shortest path for basic electrification in remote locations, while grid extension or infill — accompanied by larger-scale renewable energy and storage - may reduce diesel fuel consumption and increase electricity access in other situations.

\subsection{A Strategic Approach}

At its core, SERIG provides business case analyses of particular projects to determine technoeconomic feasibility and rough order of magnitude returns to investors and identify strategies to encourage more widespread deployment of renewable energy solutions. Because of the high renewables penetration emphasis in these projects, preliminary system integration and impact studies were also conducted, with recommendations for next steps. Applying these techniques to each project aims to reduce early stage risk and accelerate development. Cumulatively, the intent is to apply such analysis in a systematic way to multiple projects, and bring the relevant institutions and stakeholders together to process the information and facilitate development efforts, thus creating a virtuous cycle that supports broad replication and economic benefits for all stakeholders.

Diesel fuel has historically been subsidized in Indonesia ${ }^{3}$, like in many remote and developing locations, giving rise to unique market challenges that must be fully understood to effectively tailor incentives to the proper participants. To substantially reduce costs, isolated grids that are powered by diesel generators may need to deploy a high percentage of renewable energy, but this requires detailed analysis and innovative technology and controls to manage the variability of wind and solar generation. To accelerate deployment at a nationwide scale, financial incentives and targeted policies and regulations may be necessary to support early adopters, while technical assistance may advance institutional capacity development and support local entrepreneurs.

One of the key goals of the SERIG initiative is to set forth strategies for pursuing widespread replication of sustainable energy projects in remote grids. These are presented in chapters 4 and 5 of this report. The process laid out by SERIG outlines a path towards replication in Indonesia that builds off of previous work and analysis. However, in a broader sense the strategy is intended to serve as a framework that can be adapted by any government interested in enabling renewable energy development at remote locations.

\footnotetext{
${ }^{3}$ In 2014, federal energy subsidies (fuel and electricity) totaled nearly IDR 350 trillion, representing roughly $17 \%$ of total government expenditure. Recent cuts to fuel subsidies (removal of gasoline subsidy and capping of diesel subsidies) have since reduced total energy subsidies to around IDR 100 trillion annually, yet the challenges posed by fuel and electricity subsidies remain. (IISD \& GSI 2015, IISD \& GSI 2016).
} 
Other island nations and regions - including, among others, Hawaii, the Pacific Territories, Alaska, and parts of Africa - confront similar energy challenges in terms of high-cost diesel generation in isolated locations. These governments have created long-term goals and more detailed roadmaps with benchmarks and milestones to measure their progress over time. Indonesia can replicate parts of their successes while paving its own path that takes into consideration unique national and regional challenges and opportunities.

\section{Current Renewable Energy and Rural Electrification Landscape in Indonesia}

\subsection{Current Trends and Context in Indonesia}

Due to abundant renewable resources and renewed political will, Indonesia appears poised to accelerate renewable energy deployment. The Government of Indonesia (GOI) has stated its desire to gradually remove market-distorting subsidies, promote the use and development of renewable energy, encourage public adoption of energy efficiency, and restructure the price of various energy sources. However, the majority of policies implemented thus far apply principally to larger, grid-tied projects. According to ESDM, the Indonesia National Government Budget, known as the APBN, allocated IDR 2 trillion (USD 160 million) toward renewable energy development in 2015 (ESDM 2015). ESDM is calling for a five-fold increase to IDR 10 trillion (USD 800 million) for 2016, with much of that funding going to PLN for expanded RE development.

For smaller projects undertaken by the private sector, feed-in tariffs (FiT) are the primary regulatory tool and incentive for remote grid projects. The current FiT structure ranges from $\$ 0.145$ to $\$ 0.25$ per kilowatt-hour (kWh) for PV projects, depending on the project's region. Biogas FiTs for projects up to $10 \mathrm{MW}$ are set at 1,050 Indonesian rupiah (IDR) per kilowatt-hour $(\$ 0.076 / \mathrm{kWh}$ as of this writing) for medium-voltage projects and 1,400 IDR $/ \mathrm{kWh}(\$ 0.10 / \mathrm{kWh})$ for low-voltage projects. Regulations regarding a wind FiT are currently under review and are expected to be launched soon. Added to these FiTs are regional multipliers that reflect the different costs of energy and doing business in more remote parts of Indonesia. Further, provincial and district governments are required to develop an energy plan that is aligned with the national energy plan - though different provinces are at different stages of implementation. Despite these seemingly attractive FiT rates, renewable energy development in remote areas still often struggles due to the costs of working in difficult and remote terrain, high costs of T\&D infrastructure that must be borne by developers, and slow approval and regulatory requirements at the local level.

The key players directly involved with the generation and supply of electricity to businesses and households in Indonesia include PLN, independent power producers (IPPs), regional governments, individual communities and captive power producers. Financing requires that a project meet financiers' return requirements and risk preferences, as well as other relevant criteria that may vary depending on the financier.

A self-sustaining market is typically defined as one that attracts private capital, produces a return on investment, fosters competition, and provides clear price signals and ongoing incentives for increasing (operational) efficiency. While this may be a long-term goal, in the short term it is generally recognized that targeted policies and subsidies may be necessary to lay the foundation for 
clean energy development in Indonesia and elsewhere-especially in more remote locations or where fossil fuels are already subsidized.

Setting an appropriate price for FiTs is essential to create a balance between proper incentives for project developers and reasonable prices for consumers and/or wholesale purchasers of power. Most commonly, a FiT generally assumes the model of an IPP selling back to the electric utility, with management of grid integration and distribution issues left to the utility. PLN receives gap funding from the Ministry of Finance (called the Public Service Obligation) to guarantee FiT payment, though the future of these guarantees is uncertain as they are expected to be phased out. In the particular case of Indonesia and remote grids, the integration of power generated and sold under a FiT can be quite challenging and has proven to be an obstacle to successful deployment, in part because the integration costs are often complicated to calculate, not well understood, and difficult to allocate between the producer and the buyer.

As renewable energy and storage technology improves and decreases in cost (Fu et al. 2016), higher levels of RE penetration are technically and economically possible. However, without improved diesel generators and controls, high levels of intermittent renewable power may be limited in their ability to displace diesel generation. This is both a technology and policy challenge and must be effectively addressed for widespread clean energy deployment.

\subsection{Current Project Development Landscape in Indonesia}

This section aims to briefly describe the existing project development landscape for renewable energy in terms of institutional processes, requirements, project and technology thresholds, planning initiatives, and other factors. Before discussing appropriate strategies to accelerate and scale-up renewable energy development across Indonesia, it is imperative to first understand the current system. For a much more thorough and detailed treatment of this very complex topic, refer to the following references: (ADB 2015a), (ADB 2016), and (ESDM 2015).

Several institutions within Indonesia are involved in renewable energy development. Chief among them are the following:

- Ministry of Energy and Mineral Resources (ESDM). Sets broad national energy policy, planning goals, Feed-in-Tariff (FIT) rates and target regions and locations, and oversees the new and renewable energy (NRE) component of the national $35 \mathrm{GW}$ goal.

- Perusahaan Listrik Negara (PLN). State-owned national electric utility; implementer of ESDM policies while also having internal policies and targets regarding diesel fuel use reduction, increased electrification, and development of demo projects such as PV-battery-diesel hybrids in select locations.

- Ministry of Finance (MoF). Provides part of PLN's budget (that which is not generated from electricity sales - including covering subsidy costs) through the Ministry of State-Owned Enterprises and funds other Ministries that are involved in electricity generation regionally and locally.

- Ministry of National Development Planning / National Development Planning Agency (BAPPENAS). Coordinates planning for new infrastructure; involved in land acquisition for construction; evaluates performance and project outcomes; staffs Regional Energy Offices. 
- Agency for Assessment and Application of Technology (BPPT). Undertakes technology research, resource assessments, and other scientific pursuits related to energy and technology.

Other Ministries and government agencies are also involved in energy deployment and policymaking to varying degrees - especially (and increasingly) local governments. In general, private energy suppliers acting as a local utility are only allowed in very limited locations where PLN grids do not exist, though large IPPs selling wholesale power to PLN are viewed as an increasingly important part of the rapid and broad scale-up of clean energy.

The current renewable energy project development landscape is quite complicated, which many have identified as a key hindrance to rapid deployment and scale-up of renewable energy. Table 1 is an attempt to describe the existing landscape and relevant processes in somewhat simplified terms to provide a reference.

Table 1. Components of Existing Clean Energy Development Landscape in Indonesia

\begin{tabular}{|c|c|c|}
\hline Item & Who & Description \\
\hline RUPTL & PLN & $\begin{array}{l}\text { 10-year planning and expansion document, updated annually by PLN. Includes } \\
\text { new renewable projects, but only if } 10 \mathrm{MW} \text { or larger. Identifies locations and } \\
\text { technologies targeted for IPP development, i.e., locations that will receive a } \\
\text { tender to receive bids. Small projects (below } 10 \mathrm{MW} \text { ) are treated separately, } \\
\text { or are simply not included as part of the comprehensive planning process, and } \\
\text { historically have not been issued formal tenders except on rare, case-by-case } \\
\text { occasions. Instead, development of small projects has depended more often } \\
\text { than not on developers approaching regional energy offices and asking for } \\
\text { permission to develop. }\end{array}$ \\
\hline $\begin{array}{l}\text { Feed-in-Tariffs } \\
\text { (FiT) }^{4}\end{array}$ & $\begin{array}{l}\text { ESDM, } \\
\text { PLN, IPPS }\end{array}$ & $\begin{array}{l}\text { FiTs are currently in place for geothermal, hydro, biomass and solar PV. Wind } \\
\text { FiTs are scheduled to be released sometime in early 2016. ESDM issues the FiT } \\
\text { rates based on technology- and site-specific methodology; for example, hydro } \\
\text { may be cheaper to develop than biomass, hence, hydro would have a lower } \\
\text { FiT. More remote regions with higher costs have an "adder" on top of the } \\
\text { base FiT, which is determined from a system average avoided cost. There is no } \\
\text { hybrid- or microgrid-specific FiT. PLN purchases wholesale power generated } \\
\text { by IPPs as determined by the FiT and internal PLN requirements for } \\
\text { maintaining grid stability. }\end{array}$ \\
\hline $\begin{array}{l}\text { Power } \\
\text { Purchase } \\
\text { Agreement } \\
\text { (PPA) }\end{array}$ & PLN, IPPS & $\begin{array}{l}\text { For larger projects, especially wind and solar since there are so few of them, a } \\
\text { PPA is used instead of a FiT. This is essentially a direct negotiation between } \\
\text { PLN, who will buy and distribute the power, and an IPP, who will generate the } \\
\text { power and sell wholesale to PLN. }\end{array}$ \\
\hline $\begin{array}{l}\text { Local } \\
\text { Ownership } \\
\text { Requirement }\end{array}$ & IPPs & $\begin{array}{l}\text { National law requires at least } 51 \% \text { Indonesian ownership for all energy } \\
\text { projects developed by IPPs that are under } 10 \mathrm{MW} \text {. For projects } 10 \mathrm{MW} \text { or } \\
\text { greater, there is no local ownership requirement. }\end{array}$ \\
\hline
\end{tabular}

4 Though called a "Feed-in-Tariff," the actual mechanism is technically a reverse bid. Specifically, a FiT guarantees a specific price for an IPP selling wholesale power to a local utility, but in Indonesia the FiT rate determined by ESDM is the ceiling price that PLN is allowed to pay for wholesale power from an IPP. Once a location and technology are selected by PLN for IPP development, a reverse bid process is enacted in which the "FiT" rate is identified as the highest price PLN will pay, but an IPP will be selected based on the lowest bid. 


\begin{tabular}{|c|c|c|}
\hline Item & Who & Description \\
\hline $\begin{array}{l}\text { Demonstration } \\
\text { Projects }\end{array}$ & $\begin{array}{l}\text { ESDM, } \\
\text { PLN, } \\
\text { BPPT }\end{array}$ & $\begin{array}{l}\text { Both ESDM and PLN are developing a project pipeline and specific } \\
\text { demonstration projects for PV-diesel and PV-battery-diesel systems for } \\
\text { remote grids. These projects are intended to both increase } \\
\text { internal/institutional capacity and expertise with respect to renewable-hybrid } \\
\text { systems and also to provide much-needed electricity to remote locations with } \\
\text { low electrification ratios. For PLN, the RUPTL essentially defines their "service } \\
\text { territory" expansion and guides PLN's demo project development. Many of } \\
\text { these systems are still in planning and design phase, and many of those that } \\
\text { have been deployed have not performed as expected; insufficient funding for } \\
\text { Operation and Maintenance (O\&M) has been identified as one of the } \\
\text { challenges and causes of reduced system performance. BPPT has also } \\
\text { designed and installed at least one high penetration renewable hybrid (PV- } \\
\text { battery-diesel) and smart grid system on a remote island that is technically } \\
\text { promising but has experienced significant challenges. }\end{array}$ \\
\hline $\begin{array}{l}\text { Inter- } \\
\text { connection }\end{array}$ & PLN, IPPS & $\begin{array}{l}\text { For individual projects, such as a micro-hydro development or a wind-diesel } \\
\text { hybrid, the rules continue to change with regard to project boundaries and } \\
\text { balance of system responsibilities. Generally speaking, IPPs are typically } \\
\text { responsible for designing, building, paying for, and maintaining inter- } \\
\text { connection and distribution hardware such as substations and transmission } \\
\text { lines between the renewable energy project and PLN's grid, though under } \\
\text { some business-to-business agreements PLN may take on this responsibility. } \\
\text { Designs for such inter-connection hardware require approval by PLN. }\end{array}$ \\
\hline
\end{tabular}

Table 1 provides a concise overview of the existing clean energy development landscape in Indonesia. There are also numerous details, exceptions, and broader economic and institutional factors that further shape the current project development reality but are not easily described in tabular format.

For example, in Indonesia, power generation costs for different locations are not easily accessible to the public. This makes it challenging for IPPs to know if they could be cost-competitive and for policy-makers to have a clear view of potential opportunities to reduce the cost of subsidies. The landscape is different in the U.S., for example, where utilities are generally required to publicly disclose their costs of generation. This allows IPPs to determine if they can more economically provide power and thus reduce the cost of electricity for consumers.

The issue of diesel fuel subsidies is complex and changing quickly in response to global, national, and local economic and political conditions. These subsidies are currently shrinking in Indonesia, as are world oil prices. The exact mechanism(s) by which fuel subsidies are distributed and received in remote locations - and how this impacts the ultimate price of diesel-generated electricitysignificantly affects renewable energy project economics. Additionally, direct electricity subsidies for PLN may result in electric rates that are well below the actual cost of generation, making it difficult for renewable developers to compete without similar subsidies. These subsidy issues are an important part of the current energy landscape and need to be understood in detail for individual projects in order to provide targeted benefits. 
Currently many potential project developers are waiting for clear price signals in the form of newly updated and published FiTs for wind and solar PV. At the same time, PLN has issued a request for proposals for consulting on a pilot phase of its 1,000 Islands Renewable Energy for Electrification Program (REEP) that will pilot 94 PV-diesel hybrid projects across 23 islands in Nusa Tenggara Timor (NTT) region. Clearly this is an exciting, dynamic moment for new and renewable energy development in Indonesia, and effective and timely policies can significantly influence the impact and costs of new projects that will contribute to the long-term energy landscape across the country. Examples of such policies and associated barriers are explored in more depth in Section 4.

\section{SERIG Background and Prior Analysis}

The first phase of the SERIG project - implemented by NREL and Winrock International — sought to evaluate the feasibility of renewable energy projects for several remote grids across Indonesia. The purpose was to build viable business cases for the adoption of hybrid renewable energy systems in remote grids, with the hope of ultimately leading to development of the projects. While the focus of this report is on high-level strategies to help accelerate nationwide RE deployment in remote grids, an understanding of SERIG's previous project-level analysis is beneficial. Hence the key aspects of that work are summarized here. A more in-depth examination and discussion of SERIG's project analysis can be found in the previous published report (Hirsch et al. 2015).

\subsection{SERIG Pilot Site Analyses}

\subsubsection{Site Screening}

The coarse regional screening study of the SERIG project was designed to select 2-3 pilot sites for technical and economic analyses of implementing renewable energy technologies in remote grids in Indonesia. The pilot sites were chosen to demonstrate the economic value of different RE technology solutions that enable economically sustainable energy market alternatives. The pilot sites were also chosen to leverage and promote further engagement with existing clean energy efforts in Indonesia while developing a replication plan for accelerated RE deployment across other remote grids in Indonesia.

Site visits and stakeholder consultations were conducted at the top five candidate sites by the Winrock International team. Based on the overall scoring results, Winrock recommended selecting Lamandau District of Central Kalimantan and Sabu Island of East Nusa Tenggara as pilot locations for in-depth techno-economic analysis under SERIG. In addition, Sumba Island was selected as the third SERIG pilot site, where SERIG conducted a detailed grid integration analysis for wind energy in support of the initiative to make Sumba an Iconic Island of Renewable Energy. The Sumba SERIG project was selected to demonstrate the interconnection analysis and studies required to maintain a stable remote grid when adding variable renewable wind or solar energy. These three pilot locations currently have high generation cost, decent physical access, excellent RE potential, and great support from both PLN and the respective regional governments. For these reasons, pilot projects undertaken in these areas were expected to be highly successful and provide an example to other remote areas.

\subsubsection{Techno-Economic Evaluation}

Like many island communities, the islands of Indonesia are almost $100 \%$ dependent on fossil fuels for electricity and transportation, especially in rural areas. This total reliance on fossil fuels leaves 
the country vulnerable to global oil price fluctuations that can have devastating economic effects on individuals and businesses. Because PLN cannot pass the entire true cost of fuel through to the customer, PLN incurs significant revenue losses during fuel price spikes which must be subsidized with use of government funds. Electricity generation costs for PLN are over four times the U.S. average. Losses incurred by PLN and the Government of Indonesia offer mounting evidence that the status quo is unsustainable. The overall objective of a techno-economic study is to evaluate technology options using economic metrics to identify the most cost-effective solution - in this case, the most economical configuration of renewable and fossil fuel-based power generation technologies that can be deployed.

Economics are key factors in integrating renewable energy technologies into the electric power systems of remote island grids. New renewable energy projects generally require a large capital investment compared with new standard fossil fuel generators. When comparing renewable energy to traditional generation options, it is necessary to compare the high initial investment costs of renewable energy against lower initial costs of traditional generators and their future operating costs of fuel. For comparison of alternatives, it is useful to determine the levelized cost of energy (LCOE) for the various options. This allows comparison of the current generation costs to the costs of renewable energy systems that may have different capacities, investment periods, financing terms, and lifetimes. LCOE includes the initial investment, financing costs, and lifetime operations and maintenance costs, including fuel (if any).

Preliminary analysis was conducted for Lamandau District and Sabu Island by NREL and Winrock using the HOMER (Hybrid Optimization Model for Electric Renewables) modeling software. The results of the analysis are intended to assist PLN in identifying the conditions under which electricity generated from solar PV, biogas from palm oil mill effluent (POME), and wind turbines become cost-effective at these two pilot sites. For the Sumba Island pilot site, SERIG built on the feasibility study performed by Hivos International and Winrock International by conducting a grid interconnection study for adding wind turbines on this rural Indonesian grid.

\subsection{SERIG Pilot Project Summaries}

Drawing from data and analysis presented in previous reports, here we briefly review the selected sites and technologies to provide necessary background for the following chapters. Additional information on site selection and characteristics were included in previous reports, entitled Sustainable Energy in Remote Indonesian Grids: Feasibility Study for Integrating Renewable Energy Technologies ${ }^{5}$ and Sustainable Energy in Remote Indonesian Grids: Accelerating Project Development (Hirsch et al. 2015).

\subsubsection{Lamandau District}

Lamandau, located in the province of Central Kalimantan, has an electrification ratio of roughly $36 \%$. The grid serves a primarily residential base load of 1,700 kilowatt $(\mathrm{kW})$ during the day and a peak load of $2,400 \mathrm{~kW}$ in the evening. Currently, PLN relies on six diesel generators (four rented and two owned) to meet the load. Two palm oil mills studied in Lamandau emit methane gas from their effluent ponds (POME) directly into the atmosphere. Instead, systems can be installed to capture and refine the biogas for combustion to generate renewable electricity for the mills and nearby

5 This study has not been published. Please contact the authors of this report if you are interested in obtaining a copy. 
communities. Economic analysis illustrates that adding 3.5 megawatt (MW) of electricity generated from palm oil mill effluent biogas has the potential to reduce the LCOE from an estimated $\$ 0.31 / \mathrm{kWh}$ to $\$ 0.11 / \mathrm{kWh}$. This solution could potentially be replicated at the more than 600 palm oil mills across Indonesia.

\subsubsection{Sabu Island}

Sabu Island, in NTT, has an average daily load of $580 \mathrm{~kW}$ and a peak load of approximately 900 $\mathrm{kW}$. Currently, PLN relies on eight small diesel generators, all owned by PLN, though at the time of the SERIG site visit, three were in disrepair. From the perspective of the utility, solar photovoltaics (PV) combined with battery storage provides an opportunity for reduction in diesel fuel use and modest LCOE reductions (from an estimated $\$ 0.38 / \mathrm{kWh}$ to $\$ 0.35 / \mathrm{kWh}$ at the time of the analysis, which may change with oil prices and dropping solar costs). Economic analysis identified that integrating batteries with a $1 \mathrm{MW}$ solar installation would provide substantial fuel reduction while reducing the challenges associated with integrating and managing a large variable resource (solar) relative to the total load.

\subsubsection{Sumba Island}

Sumba Island, also in NTT province, was the third selected location to receive technical assistance under the SERIG project through a grid interconnection study. The electrification ratio for the entire island is estimated at about $25 \%$. There are various RE opportunities on Sumba, including wind, hydro, and PV. There are also several other entities involved in clean energy development on the island, namely under the Sumba Iconic Island initiative, formalized under ESDM Ministerial Decree No $3051 \mathrm{~K} / 30 / \mathrm{MEM} / 2015$ issued on June 1, 2015, which has established a goal of $100 \%$ electrification and 95\% RE generation to meet the entire island's load by 2020 . The published SERIG grid interconnection study for the $850 \mathrm{~kW}$ wind turbine with flywheel or other storage is contributing to the Sumba Iconic Island initiative (Oswal 2016).

\section{Strategies to Accelerate Nationwide Deployment of Sustainable Energy in Remote Grids}

The SERIG work described in the previous chapter focused on reducing early-stage risk for specific projects through techno-economic feasibility analysis. This is an essential initial step toward eventual deployment of renewable energy technologies, and such an analytical approach is generally replicable for individual projects. Techno-economic feasibility analysis is part of the broader project development process, with each successful project deployed contributing to national economic development goals. The second phase of the SERIG initiative - embodied in this report - is to set forth strategies for accelerating nationwide deployment of sustainable energy projects in remote grids. These strategies are informed by, and expand upon, the SERIG pilot experiences described in Chapter 3. However, in a broader sense the strategies are intended to serve as a framework that can be adapted by any government interested in widespread deployment of renewable energy in remote locations.

Several reports and organizations have attempted to outline general processes for replicating renewable energy projects at scale, including but not limited to the U.S. DOE's Energy Transition Initiative Islands Playbook, which offers a guide to the steps required for successful implementation of renewable energy projects in island settings (US DOE). This report intends to complement such 
work by drawing on lessons learned and in-country experience to suggest a strategy and targeted execution pathways for Indonesia to expand deployment of renewable energy in remote grids nationwide.

The elements of a nationwide deployment strategy are to: (1) establish goals and coordinate actors, (2) engage and develop market participants, (3) assess and publicize opportunities, (4) provide local proof of concept, (5) facilitate favorable market conditions for renewables, (6) channel finance to remote projects, and (7) enable flexible, innovative business models. For each strategic element, pathways to execute that element within Indonesia are suggested. Figure 1 summarizes these strategic elements and execution pathways. The elements and pathways in Figure 1 are not necessarily ordered sequentially; the exact order of steps for pursuing a nationwide deployment strategy will depend on the status of current efforts both regionally and nationally, as well as the overarching socio-political climate.

\section{Strategic Elements}

Establish Goals and Coordinate Actors

Engage and Develop Market Participants

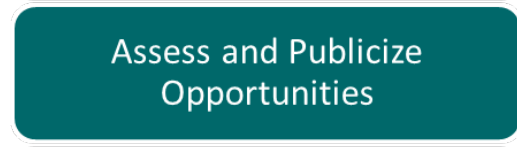

Provide Local Proof of Concept

Facilitate Favorable Market Conditions for Renewables

Channel Finance to Remote Projects

Enable Flexible, Innovative Business Models

\section{Execution Pathways for Indonesia}

- Strengthen coordination among relevant ministries and task forces

- Provide a resource hub for knowledge, assistance and outreach

- Perform nationwide opportunity assessments

- Provide standardized guidance for feasibility studies

- Invest in a few, high-quality demonstrations and work through problems

- Strengthen and clarify the regulatory framework

- Benchmark remote tariffs to local fuel costs

- Bundle projects for development

- Financially back remote projects where appropriate

- Support business models tailored to community circumstances

Figure 1. Elements of a deployment strategy with suggested execution pathways for Indonesia

It is important to note that the execution pathways for Indonesia proposed here are by no means intended to be exhaustive. Within each of the seven strategic elements, any number of activities could potentially be undertaken. The goal here is rather to identify a limited number of high-priority actions for the Government of Indonesia that will help lay an effective groundwork for further efforts to widely deploy renewable energy in remote grids across Indonesia.

The remainder of this chapter is broken into sections, with each section addressing one of the seven strategic elements to accelerate nationwide deployment. Each section offers a brief overview of the strategic element and describes one or two specific pathways for executing that strategic element in 
Indonesia. Most sections feature a brief case study highlighting how the strategic element or execution pathway has been successfully implemented in another country, region, or community.

\subsection{Establish Goals and Coordinate Actors}

Accelerated, widespread deployment of renewable energy in remote grids will necessarily involve a variety of public and private actors. It is crucial that these public- and private-sector entities coordinate with one another as they work towards a single national goal. While it begins with setting clear national goals, outlining specific responsibilities and establishing concrete mechanisms for coordination amongst actors will ultimately be necessary to help provide the kind of clarity and consistency that can increase investor confidence, reveal opportunities to leverage finance, and align incentives. As of the end of 2012, 138 countries worldwide had established renewable energy targets (WWF 2013). In remote settings, the dispersed and often disconnected nature of stakeholders renders effective coordination to achieve these targets even more critical.

\section{Case Study 1. Hawaii Clean Energy Initiative Sets 70\% Renewable Energy Goal by 2030}

The Hawaii Clean Energy Initiative (HCEI) was launched in 2011 to provide a framework to help shift the State of Hawaii's energy mix from $90 \%$ imported fossil fuels to a $70 \%$ clean energy economy by 2030. The HCEI is structured for collaborative engagement and partnerships with all stakeholders. A core Executive Management Team (EMT), consisting primarily of state and federal government representatives, provides guidance to action groups and facilitates resource and solution sharing. The HCEI Advisory Board, representing utilities, private industry, NGOs and academia, works closely with the EMT to provide input on priority issues and challenges and help drive the initiative forward through financing and other support.

Since developing its initial clean energy roadmap, the HCEI has met many of its goals. Hawaii currently enjoys a robust clean energy industry, with innovation accelerating at a rapid rate and stimulating economic growth. In the transportation sector, there are presently over 2,921 electric vehicles (EVs) on Hawaii's roads, supported by over 450 publicly available charging stations statewide. In renewable energy deployment, the state is investing in smart infrastructure and exploring next-generation technologies. In 2013, Hawaii reached the record milestone of generating $18 \%$ of its energy from renewable resources-well ahead of its target of $15 \%$ by 2015 . As of the same year, the state had reduced overall energy consumption by $15.7 \%$.

Reference: Hawaii Clean Energy Initiative 2016

\subsubsection{Execution Pathway for Indonesia: Strengthen Coordination Among Relevant Ministries and Task Forces}

Indonesia is well on its way with the recently announced $35 \mathrm{GW}$ plan-including goals of $25 \%$ renewable energy by 2025 and near-universal electrification by 2020 . These targets offer excellent examples of national goal-setting. To turn these goals into reality, it will be necessary to coordinate efforts by developing detailed action plans with timelines, roles and responsibilities of the various actors, and budgets. Designating a cross-ministry task force can help provide clarity regarding responsibilities and facilitate public sector coordination across the various actors.

A step that could help accelerate progress towards achieving the clear goals and targets already outlined by the Government of Indonesia may be to strengthen coordination across the various 
ministries and task forces involved. Within large and complex governments this can often prove a difficult undertaking - one that plagues nations of every sort. One step could be to appoint an interministry task force explicitly responsible for coordinating implementation activities across ministries. As discussed in section 2.2, there are a multitude of actors and agencies involved in remote RE deployment efforts, and it is an ongoing and critical task to ensure that all actors are working in concert from a comprehensive plan in which all are vested. Assigning a task force that is not only responsible, but also empowered with the necessary tools, for communicating and coordinating activities across agencies can help facilitate agency cooperation. Such a task force could include representatives from each of the relevant bodies (e.g., ESDM, PLN, BAPPENAS, Ministry of Finance, and others). NREL has helped organize several task forces such as this within the Pacific Territories and Freely Associated States with positive results. While Indonesia offers a larger and far more complicated context, similar efforts are likely to prove advantageous.

\section{Case Study 2. Pacific Territories Establish Energy Task Forces}

Under the direction of the U.S. Department of the Interior, NREL facilitated the establishment of cross-ministry energy task forces in Guam, American Samoa, and the Commonwealth of the Northern Mariana Islands. These task forces were composed of technical and policy experts representing a broad range of stakeholders, including utilities, energy offices, academia, commercial sectors, environmental agencies and legislative members. The task forces were given responsibility to identify comprehensive and implementable energy strategies that would accelerate the development of renewable energy and energy efficiency measures in the Territories. Since their inception in 2011, these energy task forces have led to the development of coordinated, strategic energy plans and energy action plans that have set the stage for widespread energy transition in the Territories.

\section{Reference: DOI-OIA 2016}

There are existing efforts within the GOI that may serve as a starting point for expansion into a fullfledged task force. One emerging and promising example is the Sustainable Energy Access Working Groups that are now in place to determine how to best use $\$ 5$ billion (USD) of lending made available through 2019 by the Asian Development Bank and others. ${ }^{6}$ Another starting point may be the recently initiated New and Renewable Energy (NRE) Project Management Unit (PMU) wing of ESDM. The NRE PMU has been chartered as the implementing arm for ESDM's community electrification programs, and could serve as a basis for a larger inter-ministry remote RE task force by bringing representation from PLN, BAPPENAS, Ministry of Finance and other relevant bodies into the NRE PMU. ESDM's Program Indonesia Terang (Bright Indonesia), which aims to electrify 12,000 remote villages mostly in six eastern provinces of Indonesia, is an excellent and promising example of one such thoughtful and coordinated approach. At the same time, other sources suggest that the GOI has also appointed PLN to carry out electrification efforts on its behalf (ADB 2016). These various efforts could be reconciled into a single, coordinated effort under a joint task force.

6 Personal communication with Mike Crosetti, PT Castlerock Asia, 10/23/15. 


\subsection{Engage and Develop Market Participants}

Efforts to deploy sustainable energy in remote grids necessarily go beyond the technical installation of individual projects. Developing a successful market will require engagement of all stakeholders involved - from the top levels of government and industry leadership all the way down to the workforce that will build and maintain infrastructure and the end-users in the communities being served. This includes building confidence in new technologies and their impacts, building construction, operation, and business capacity, and developing support within local communities for new projects. The often isolated nature of remote grids can leave them much more vulnerable than other projects to both technical and operational risks, rendering stakeholder development even more important in these communities.

\section{Case Study 3. Alaska Builds Indigenous Capacity to Install and Maintain Wind-Diesel Systems}

Chaninik Wind Group is a consortium of 4 remote rural communities in southwestern Alaska. All the communities are isolated geographically and electrically, with no road access-airplanes or boats are required to ship in diesel fuel and all other goods. Electricity without subsidies sells for over $\$ 0.50 / \mathrm{kWh}$ (US). Over the past five years, these communities have worked together to install wind energy systems with very high penetration rates into the diesel electric grid. This has required substantial integration and controls development, including lithium-ion batteries and fast-acting secondary dispatch in the form of useful heat when the wind turbines are producing more energy than the primary electrical system demands. Key to the success of these systems is the concerted human capacity development and training effort that has occurred. All the communities operate their own utilities, and have contributed personnel to the installation, operation and maintenance of the wind turbines. Lessons learned in one of the communities have been applied to the other communities with continual process and performance improvements. At least one community is now operating with diesel off for almost $30 \%$ of the time, and as battery prices continue to drop and other communities are able to secure more storage they expect higher levels of diesel-free operation.

\section{References: U.S. DOE 2014; Waldholz 2016}

Establishing a designated center to support renewable energy stakeholder engagement and education activities can be an effective strategy for market development. Such centers can serve multiple roles: they can maintain a clearinghouse of information and guidance for remote grid renewable energy projects, offer tailored technical assistance to aid communities and developers as they pursue sustainable energy projects, train workforces through workshops and other trainings, promote remote RE through targeted outreach campaigns, and serve as innovation hubs to foster development of renewable energy technical and business capacity. Such a center may even have a role in connecting developers with appropriate financing.

\subsubsection{Execution Pathway for Indonesia: Provide a Resource Hub for Knowledge, Assistance, and Outreach}

The remote renewable energy landscape in Indonesia is challenging. The multitude of actors and potential opportunities, as well as widespread misunderstanding about the capabilities and limitations of various technologies and business models, contribute to uncertainty around remote renewable energy prospects. Added to this is a lack of clarity regarding the precise legal and regulatory protocols for development of remote sites. To address this issue, a centralized hub for 
knowledge and assistance with respect to small-scale remote renewables in Indonesia could serve as a focal point to guide all stakeholders and facilitate communication. The dispersed and often isolated nature of stakeholders in remote areas makes it even more critical to establish a centralized hub and focal point to facilitate effective communication and engagement. Such hubs have worked well in other contexts to help accelerate renewable energy deployment and electrification efforts. One such example is the Clean Energy Solutions Center, which maintains a network of subject-matter experts who are available at no-cost to answer technical and regulatory questions from stakeholders in developing nations interested in increasing deployment of renewable energy. A similar, more targeted service focused on remote renewable energy solutions could be housed within a larger Indonesian renewable energy center.

Indonesia does not need to start from scratch. Several ongoing efforts could be leveraged or merged to create a single, one-stop hub for remote renewable energy and electrification resources. For example, the Danish International Development Agency (DANIDA) is currently running the Energy Efficiency and Conservation Clearing House Indonesia (EECCHI) - a clearinghouse of information regarding building energy efficiency which is housed within EBTKE. The Indonesia Investment Coordinating Board, BKPM, offers resources and support intended to facilitate and streamline foreign investment in Indonesia. The Agency for the Assessment and Application of Technology, BPPT, carries out research and analysis across a range of technical programs that includes renewable energy resources and technology. And in August 2015, EBTKE released a "Practical Guide to Investment in Renewable Energy" that attempts to highlight the key regulations and policies relevant to potential renewable energy investors and developers in Indonesia.

While these efforts focus on energy more broadly they could be consolidated - and supplementedto create a single renewable energy center tasked with knowledge development, assistance, and outreach, all focused on accelerating renewable energy investment in Indonesia. A key component of this could be a dedicated remote renewable energy division within the larger center. To have the highest impact relevant to Indonesia, such a remote RE center could focus primarily on educating stakeholders about technology, business, and regulatory issues pertinent to remote renewable energy development, and could provide targeted outreach campaigns and applied technical assistance to facilitate project development and investment in remote areas. An immediate opportunity exists to leverage current efforts to establish a Clean Energy "Center of Excellence" on Bali. A dedicated remote renewable energy and electrification division could be established within the Center of Excellence that focuses on this sort of stakeholder engagement and project facilitation as one of its core functions.

\subsection{Assess and Publicize Opportunities}

Assessing renewable resource availability and evaluating the feasibility of potential projects is costly and entails risk. This problem is compounded further within remote contexts due to the typically small size of projects and sheer number of potential opportunities. However, governments can help spur the market by taking some of the responsibility for opportunity and feasibility assessment and offering bankable projects to the market.

Indonesia has undertaken this process as part of its $35 \mathrm{GW}$ plan-identifying 108 grid-tied, conventional and renewable energy opportunities to be developed to meet the $35 \mathrm{GW}$ goal. The SERIG project has begun a similar process for remote sites - starting with screening of the 900 isolated diesel grids across Indonesia, selecting three on which to perform detailed evaluations of RE 
options and economic pre-feasibility studies, and ultimately identifying three bankable projects (one in conjunction with ADB and DANIDA). The rigorous screening process used by SERIG could serve as a starting point for further identification of potentially bankable remote grid projects across Indonesia. The 1,000 Islands project, led by PLN and the World Bank, has similarly begun to identify several potential solar-diesel hybrid locations throughout the country. Scaling up these efforts is unlikely to happen organically; it will require a concerted effort across the highest levels of government. A resource hub such as that described in section 4.2.1 could be well-suited to take on the role of performing nationwide opportunity assessments and disseminating that information.

\section{Case Study 4. CIRCLE Assesses Biogas Opportunity}

Capacity for Indonesian Reduction of Carbon in Land Use and Energy (CIRCLE) has engaged 23 palm oil mills toward the goals of reducing emissions and improving sustainability. In the past four years the Winrock team has completed sustainability assessments for all 23 mills, biogas pre-feasibility assessments for 21, and in-depth feasibility assessments at 15 . Through the work of CIRCLE and its partners, two projects are in the commission stage, another two are under construction, and eight are out for bids. These projects have a total capacity of $24 \mathrm{MW}$.

\section{Reference: Winrock International 2015}

\subsubsection{Execution Pathway for Indonesia: Perform Nationwide Opportunity Assessments}

The scope of intervention required to achieve remote renewable energy goals in Indonesia necessitates action from the top. Indonesia's 35GW plan calls for 108 new power plants to be builtan average capacity of $324 \mathrm{MW}$ per plant. With relatively few, large plants it is a comparatively simple matter to manage and evaluate each site and draw developer interest. Compare this to the literally thousands of islands and communities across the country that require small systemstypically less than a hundredth of the size of projects on the $35 \mathrm{GW}$ plan - and it is clear that identifying and soliciting interest in thousands of small sites will be a large undertaking requiring a similar, if not greater, effort. A national campaign to assess viable opportunities and point developers and/or PLN towards the most likely sites first will be a key step in ramping up electrification efforts.

An Indonesian remote RE opportunity assessment would need to consider several factors: quality of available renewable resources, existing transmission and distribution infrastructure, locations of communities and unmet demand, and current costs of alternatives, as well as other intangible factors such as community acceptance. There have been some efforts to evaluate resource availability on a national scale, such as the current DANIDA-funded national wind assessment, but data gaps still exist for many renewable resources including solar and small-scale geothermal. In considering resource information, the question of data resolution must also be carefully considered. Wind data, especially, can vary at quite small geographic scales and hence detailed modeling with physical meteorological towers is often necessary.

Once resource quality has been adequately assessed and mapped for all resources, that information must be reconciled with information on where communities are located and infrastructure either exists or is planned. ESDM is currently undertaking an effort to identify and map thousands of small 
villages across Indonesia that currently have no established power infrastructure. This assessment will be a critical piece that could feed into a national opportunity assessment.

As the decision to develop a project typically comes down to a question of economics, the final component will be data on the current cost of generation (where it exists) at remote locations. A key aspect of this will be detailed, publicly-available data on the current cost of generation at each of PLN's 900+ diesel sites across the country. Once all of these pieces (resource quality, community and grid infrastructure, current costs) are brought together, one can begin to identify sites meriting further investigation and feasibility analysis (see next section below). This next phase of evaluation can be undertaken either by the GOI directly or by developers - a matter that will ultimately depend on the specific policy and regulatory environment established to support such efforts. The current $35 \mathrm{GW}$ plan for utility-scale additions has pre-identified sites ready for tender to developers. Whether it is feasible to replicate that sort of identification and tendering process for thousands of much smaller projects is yet to be seen, but this would be the ideal.

\subsubsection{Execution Pathway for Indonesia: Provide Standardized Guidance for Feasibility Studies}

Once potential opportunities have been identified on a broad, national scale, they must be evaluated in further detail to assess the technical, economic, and social feasibility of their actual development. Ideally this step would be done by the Government of Indonesia, but it can also be left to developers under the right regulatory and policy framework. Should this step be left to developers, standardized guidance on best practices and output metrics for feasibility studies can help ensure developers are providing thorough, high-quality proposals from the start and eliminate low-quality proposals. In this case, standardization could also help streamline PLN's review process by ensuring that developer proposals follow the same format and can be more easily evaluated. On the other hand, should PLN or ESDM be directly responsible for these detailed studies and subsequent tenders, such guidance will assist the regional offices that perform the studies and ensure that potential projects can be accurately compared and will be able to secure financing.

An effective feasibility study should provide background research on the techno-economic climate for renewable energy, followed by a detailed resource assessment based on available data. GIS mapping tools should be used to provide information on the quality of renewable resources, land availability, current cost of generation, current power source structure, electrification ratio, current consumption, and protected forest and other environmental protection features. To optimize the renewable energy contribution, many technical decisions factor into such systems. The general components that should be included in a standardized renewable energy system feasibility study are described below:

- Electrical Baseline Generation. A baseline model of the existing generation and distribution system should be developed, including annual loads, inventory of power station generation units, distribution system characteristics, loads by feeder, and fuel consumption and costs.

- Energy Efficiency Measures. After the electrical power system baseline is understood, energy efficiency and renewable energy system options should be evaluated from an economic perspective. Energy efficiency opportunities can be evaluated from both the 
consumer-side (such as lighting, appliance, and insulation measures) and from the supplyside (such as reductions in transmission losses and improvements to generator efficiency).

- Renewable Energy Options. Renewable energy generally requires a large capital expenditure compared to standard diesel generators, but typically results in decreased spending on fuel and maintenance. Hence a cost-benefit analysis, comparing the various renewable energy technology options, including resource availability, and assessing the interplay of renewable energy with existing generation, must be evaluated.

- Impact Analysis on Electrical Infrastructure. Because intermittent generation from renewable energy systems - particularly wind and solar-is more challenging to incorporate into small island systems than conventional, dispatchable generation, the economic analysis should be followed by better characterization of the renewable resources, identification of sites for systems, and analysis of the impact (immediate or future) on the existing distribution system and generation stations. These grid integration studies generally include power-flow analysis, steady-state stability analysis, dynamic and transient stability studies, and protection/coordination fault studies.

- Recommendations and Roadmap. Thorough feasibility analysis offers insight into the optimal and most economic configuration of renewable energy, storage, and conventional backup systems at the specific location in question, which can translate to a roadmap for project development.

The pre-feasibility studies under the first phase of SERIG (see Chapter 3) completed the first three components of this framework at Lamandau and Sabu Island, while the Sumba wind interconnection analysis provided the impact analysis and recommendations. Together, these five proposed renewable energy feasibility study components provide a framework that could be adapted to provide standardized guidance on performing effective feasibility studies.

To ensure proper application of a standardized feasibility study procedure, local staff should be trained on both performing and evaluating these studies. This type of guidance and associated training could be implemented by the resource hub described in section 4.2.1.

\subsection{Provide Local Proof of Concept}

Before they readily commit to develop remote grid renewable energy projects, most stakeholders unfamiliar with the technology will likely want to see that it works first - not only technically, but also financially and politically. Hence developing one or more sites to serve as a local proof of concept can help reduce investor uncertainty and spur the market. This is even more important in remote areas where isolated stakeholders often tout unique local circumstances as potential project barriers. In addition, initial proof-of-concept sites can serve as valuable, hands-on learning tools to help build stakeholder understanding while informing future policy and regulatory decisions. In Indonesia, the SERIG project has identified and primed three different sites that could serve as readily accessible proof-of-concept examples, spanning wind, solar, and biogas technologies. 


\section{Case Study 5. Solar PV Demonstration on Lanai, Hawaii Paves Way for Further Developments}

With more than 270 sunny days per year, La Ola, on the island of Lanai, Hawaii, is a near-ideal location to build a solar farm. Lanai Sustainability Research (LSR) did just that by constructing the $1.2 \mathrm{MW}$ La Ola photovoltaic (PV) solar farm to operate on Lanai's $4 \mathrm{MW}$ grid with the objective of providing clean power to the island's residents and resorts. Included in the design is a battery storage system with a rated power of $1.125 \mathrm{MW}$ for a 15 minute duration to provide ramp control, frequency response, and power quality management. Following the commissioning of the battery storage system, the Lanai solar farm coupled with the storage solution is able to deliver uncurtailed solar power to the small Lanai grid. The large solar farm on Lanai was one of the first solar-with-storage projects integrated into Hawaii's small island diesel grid. This project helped demonstrate the design concept of solar plus storage, paving the way for similar projects now being implemented on Kauai, Maui, and Oahu in Hawaii.

\section{Reference: Castle \& Cooke 2012; Gahran 2015; Energy Storage Association 2016}

\subsubsection{Execution Pathway for Indonesia: Invest in a Few, High-Quality Demonstrations and Work through Problems}

In Indonesia, several initiatives have set their sights high to develop multiple remote renewable energy projects across a region. One such example is PLN's recent efforts to develop 94 PV-diesel hybrid sites in consultation with Germany's KfW Group. However, before setting sights on widespread replication, it is important to ground-truth preliminary technical and financial analyses and ensure that both the technology and business cases are viable. In many cases, projects may not prove technically or economically viable initially and adjustments may be required after deployment. Hence the value of establishing local proof of concept cannot be underestimated. At this stage in Indonesia, it may be wise to focus resources on fewer, high-quality demonstration projects spanning different geographies and technologies to provide the broadest base of experience to the widest and most relevant audiences.

\section{Case Study 6. Sumba Iconic Island Initiative Aims to Provide Demonstration}

The Government of Indonesia launched the Sumba Iconic Island (SII) initiative in 2010 jointly with the support of HIVOS, a Netherlands-based non-governmental organization (NGO). The initiative aims to achieve the following by 2025 :

- Increase the electrification ratio on the island of Sumba from a current level of approximately $30 \%$ to $95 \%$

- Increase the share of electricity produced from renewable resources on Sumba from approximately $15 \%$ to $100 \%$.

In addition to providing the people of Sumba with sustainable, universal electricity access, the SII initiative is intended to provide a model for renewable energy-based access that can be replicated elsewhere in Indonesia.

\section{Reference: Winrock International 2010}

Further, it is critical to follow up with necessary analysis and adjustments to ensure that these projects perform as expected and provide as much educational value as possible. Oftentimes demonstration projects may initially encounter problems. Rather than abandon them at the first signs 
of trouble, however, their purpose and value is in learning how to overcome those challenges. Hence committed and thoughtful follow-up is equally as important as the initial demonstration effort. Developing demonstration projects and working through problems could be one role for a renewable energy resource hub as described in section 4.2.1. Such efforts may require a designated, first-loss demonstration fund that is insulated from government guidelines that often punish programs that incur losses on government investment and hence discourage the use of public funds to test new and innovative systems and business models.

In Indonesia, several projects — including those identified by SERIG — are already underway that may serve as examples of such demonstration projects.

\section{MW PV Solar Farms in Bali}

An IPP has installed two 1 MW PV solar farms in KarangAsem and Bangli, Bali. The IPP, PT Solar Energy INDOTAMA, is setting up the project to be transferred to local government ownership upon completion. Law 30/2009 on Electricity and associated implementing regulations provides a legal mechanism for national and local government funding of electrification infrastructure and the designation of non-PLN electricity business. The law allows local governments and co-ops to produce and sell power, but they must build their own distribution system without subsidy. The project is producing electricity to sell to PLN at $\$ 0.25 / \mathrm{kWh}$.

\section{BPPT Smart Grid Facility, Bilacenge, Sumba}

Bilacenge is the site of a micro-grid demonstration project consisting of a $500 \mathrm{~kW}$ on-grid PV plant with batteries. The plant is using thin film panels as they do not de-rate in heat and are not as influenced by cloud cover. The PV farm only drops $20 \%$ during cloudy days and has a $16 \%$ electricity conversion efficiency. The system uses Vanadium Redox batteries for storage.

The micro-grid project is funded by BPPT and has 'smart' communications between the PV-storage site and PLN's regional power plant to manage electricity production. The smart grid is currently managing the power it delivers to PLN by providing constant power from the PV panels and storage system.

\section{SERIG Locations in Kalimantan and East Nusa Tenggara}

With much of the initial analysis and leg-work done and an interested network of stakeholders, the three sites at Lamandau, Sabu, and Sumba identified and analyzed by SERIG are poised to be developed as valuable demonstration sites. With three different renewable technologies (solar PV, biogas from POME, and wind), the sites taken together could serve to demonstrate a suite of hybrid options that may be replicated elsewhere. The sites could even serve as a collection of "living laboratories" for learning and teaching purposes, in partnership with a centralized Indonesian resource hub for remote renewable energy. Potential financiers or project developers for these sites include PLN, ESDM, local governments, private-sector developers, development banks such as the World Bank and the ADB, private-sector banks, and NGOs.

\subsection{Facilitate Favorable Market Conditions for Renewable Energy}

With the ultimate goal of developing a healthy, self-sustaining remote grid renewable energy market, it is important that policymakers provide clarity, consistency, and simplicity in policy and regulation design. In many cases, electricity regulations may not be specifically designed to accommodate remote projects or new and renewable technologies. Additionally, uncertainty for developers and 
investors is often greater for smaller and more remote projects, making active market facilitation ever more critical in these contexts.

Fuel subsidies, feed-in-tariffs, tax structures, import duties, quality standards, and grid extension plans can all affect the viability and performance of remote renewable energy markets and contribute to favorable market conditions. Streamlining processes for doing business in remote grids can also help alleviate regulatory burdens that often prevent developers from entering the market. Licensing, registration, and permitting requirements can be simplified and targeted to help developers navigate what is often a complicated process.

\subsubsection{Execution Pathway for Indonesia: Strengthen and Clarify the Regulatory Framework}

One of the principal concerns of developers in Indonesia is that some aspects of the legal and regulatory framework for renewable energy development in remote areas are unclear and do not elicit the confidence of potential investors. ${ }^{7}$ In formulating and refining a framework to guide RE development, both predictability and transparency are critical. When designing regulations and practices to encourage widespread RE development, the mechanism and packaging of relevant regulations should be made publicly available and easily understood (transparent) and empower developers to understand what to expect, when to expect it, and how it will work (predictable).

The size and scope of a development and regulatory framework can be large and affect numerous aspects of government at multiple levels. Rather than discuss every potential aspect of such a framework, some key elements identified by SERIG within Indonesia are highlighted below:

- Interconnection Requirements. As explained in Table 1, regulations around interconnection requirements for power producers can at times be uncertain. In most cases, IPPs are responsible for the cost of building and maintaining transmission and distribution equipment to connect to PLN's grid, with prior approval from PLN. However, in some cases this can be negotiated as part of a PPA between PLN and the IPP. Standardization and clarification of which party will be responsible for transmission and distribution upgrades and how they will be funded and maintained can help provide much-needed certainty for investors. For remote grids, unconnected to PLN's primary grid, it remains unclear what exactly will happen if and when the national grid ultimately reaches those locations. Developers of microgrids need some certainty that their assets will be incorporated into the main grid or that they will otherwise be compensated when the grid arrives. A clear and consistent policy framework that outlines exactly what will happen in these cases will be a key feature of any remote RE regulatory framework.

- Cost Clarity. In order to identify cost-competitive renewable energy solutions, developers first must understand the current cost of diesel generation. If a developer designs and plans a project without knowledge of the cost of diesel, it could find that its project is not financially viable only after already investing significant resources in the early project phases. If PLN were to provide publicly available and easily accessible data on the current cost-of-generation at specific locations and sites across Indonesia, it could help eliminate this risk for developers and encourage them to pursue only projects that will provide financial savings for both consumers

\footnotetext{
${ }^{7}$ According to interviews and personal communications with private entities in Indonesia.
} 
and government subsidy funds while still yielding revenue for the developer. Importantly, remote RE projects must be compared to the true cost of generation rather than the subsidized price. Hence, cost-of-generation data should be released that reflects this. Ideally this information would be incorporated into a nationwide opportunity assessment as described in section 4.3.1. At the very least, however, it should be readily and freely available upon request.

- Investor Confidence. Investors require certainty that capital invested will be able to provide a reasonable return. If generation assets are built and then left unused, or are unable to access subsidies and FiTs, then investors will quickly lose confidence and cease investment. Hence predictability in the regulatory framework provides much-needed certainty for investors that can help boost the inflow of capital investment. This can often be difficult in an environment in which political turnover creates uncertainty at the highest levels that then trickles down. One option may be to insulate the regulatory framework by setting review periods independent of political timelines. Written regulatory guarantees that new power generators will be compensated in some way for their investment — either by selling power as an IPP or being compensated directly for their assets - can also help provide a level of certainty for investors. In the U.S., for example, a "take-or-pay" system has been applied effectively that ensures local utilities will either "take" power generated from an IPP at a pre-negotiated rate or "pay" the developer for its assets.

- Domestic Content Requirements. Under current policy, renewable energy projects that are less than 10MW must contain at least 51\% domestic (Indonesian) content and have at least 51\% Indonesian ownership. This can severely hinder the ability of foreign entities to channel their technology, expertise, and capital into developing remote grids in Indonesia. To get around domestic content requirements, foreign companies may partner with local entities that are illequipped to properly support projects. While domestic content laws have the noble intent of fostering a domestic industry, technical and business capacity must first be developed in-country. To help achieve this, domestic content requirements could be eased in the immediate term to give foreign expertise and experience more open access to the market. This can begin the transfer of expertise and capacity to local businesses and jump-start an active domestic market. Domestic content laws could then be ramped up slowly over time to support local industry as it develops.

\subsubsection{Execution Pathway for Indonesia: Benchmark Remote Tariffs to Local Fuel Costs}

Indonesia is home to a vast array of diversity — both diversity of resources as well as cultural, social, and geographic diversity - across its tens of thousands of villages. While this wealth of diversity endows the country with great opportunity, it also means that there is no single "silver bullet" solution for remote grids - each opportunity will need to be evaluated independently to find the best renewable energy solution that meets the specific needs and capabilities of each community.

While most feed-in tariffs are typically based on a levelized-cost analysis of generating power from a specific renewable resource, extreme local variability can affect location-specific installation and operation costs, meaning that regionally-based FiTs are often inappropriate for the community scale or for remote locations. Ideally, an analysis would be done to determine the cost of renewables at each unique site to set a site-specific FiT. However, with thousands of remote sites - and in the absence of this kind detailed, resource-intensive analysis - a more appropriate remote FiT may be one that is "technology-agnostic" and based on the current cost of alternatives at a given site (e.g., 
diesel generation or, in some cases, no generation), which is a known quantity for PLN. Such a scheme might set a flat RE tariff for each unique remote location at a rate below PLN's unsubsidized local generation costs (for example, setting it 10\% below the local unsubsidized cost of diesel). This would promote renewable energy deployment by providing RE developers with a fixed FiT, independent of a particular RE technology, while reducing the total subsidy obligation that must be paid by the Government of Indonesia - a win-win situation for both taxpayers and energy consumers. Such a tariff scheme would then put the onus on developers to evaluate technology options and identify the specific renewable technology that would be most cost-effective given local conditions. These flat RE tariffs - benchmarked to local diesel costs — would be comparatively straight-forward to implement in the immediate-term and guide developers preferentially to locations where the unsubsidized cost of generation is highest. Conversely, sites at which the cost of diesel remains well below the cost at which renewables can compete would - at least for the time beingbe left untouched until either the cost of diesel rises, the cost of renewables falls, or the policy is revisited several years down the road after a local RE industry has been established.

These FiTs should be designed with the ultimate intent of phasing out financial support through a slow and gradual, step-wise reduction of the FiT. As RE technology begins to be deployed more rapidly, local capacity is developed, and costs fall, the RE FiT could be slowly ratcheted down over time until the tariff paid to remote grid power producers reflects only a small margin over their cost of generation. This would provide more certainty and an easier transition for developers, rather than the abrupt market shocks inherent in a two-step scheme in which the FiT experiences a single decrease after a set number of years (usually 8-10) from its initial enactment. In addition to a gradual phase-out, offering different FiT pricing for flexible baseload vs. intermittent power supply may help the grid fortify its resiliency. Most importantly, engaging both public and private stakeholders in an open and ongoing dialogue is essential toward designing and implementing an effective FiT scheme for remote projects in Indonesia.

\subsection{Channel Finance to Remote Projects}

Providing transparent and consistent policy is especially important to reduce market uncertainty and attract private investment, yet in some cases this still may not be enough. For many remote grid projects, the systems are small, risk is perceived as high, and financial returns are considered lowhampering the ability of such projects to secure traditional financing even in the presence of favorable market conditions. However, appropriate government actions can help guide traditional financing to these small, remote projects that may otherwise be overlooked or considered imperfect investments. Aggregating several smaller projects into a single investment can help diversify risk and attract larger donors and investors. Financial tools such as loan guarantees and concessionary finance can also help increase the flow of capital into the market. In some cases, establishing a financial intermediary (or designating existing financial institutions) to serve as a channel for remote renewable energy project financing can be an effective tool. Such intermediaries can help leverage finance from multiple donors, investors, and government ministries.

Ultimately, steps that reduce overall risk (such as proof of concept and well-designed quality standards) can serve to boost investor confidence and increase the availability of financing. 


\subsubsection{Execution Pathway for Indonesia: Bundle Projects for Development}

Indonesia is home to an estimated 82,000 rural villages with a total population of 120 million - an average of just 1,500 per village. With those kinds of dispersed populations, it can often be difficult for power producers to achieve economies of scale and the favorable economics that go with it. In addition, smaller systems often carry higher levels of risk from default, demographic changes, and other unforeseen circumstances. In a remote system there are frequently also up-front costs incurred in gaining site access and providing infrastructure. All of these factors make financing more difficult and projects less attractive to developers.

Much like an insurance company prefers a large customer base to hedge against risk, or an investor seeks a diversified portfolio, energy project developers and investors will be more likely to take on small, remote projects if multiple projects can be bundled together into a package. ${ }^{8}$ Such aggregation techniques can provide a larger project portfolio to help attract better financing terms and help developers achieve economies of scale. Projects could be bundled by a range of characteristics, including size, technology, or even cultural factors and tendered as a single RFP. Alternatively, the right to develop all projects within an entire area or region could be granted to a single developer in a bundled, concessionary model, with certain service quality and coverage stipulations to protect consumers. In some cases this is already happening in Indonesia - an example being the bundling of 94 potential solar PV sites to be evaluated and engineered under a single tendered contract.

\subsubsection{Execution Pathway for Indonesia: Financially Back Remote Projects where Appropriate}

Lack of available financing is consistently identified as a barrier to more widespread remote RE deployment - in Indonesia and around the world. In remote locations, projects are often very small with a low return on investment and high perceived risk, deterring most traditional investors. Aggregation of projects, as described above, is one way to address concerns over project size. However, other financial tools can also be used to help channel private finance and donor support to developers in need of financial backing.

Tools such as government-backed loan guarantees and foreign currency protections can help reduce investor risks associated with operating in remote and developing regions and help encourage finance. Many governments in emerging markets have established national financial intermediaries to further leverage donor support and private-public funds at a scale more appropriate for small, remote projects. In some cases these intermediaries oversee other market activities such as training or outreach (Walters 2015). Hence, in Indonesia, such an intermediary could be a subsection of the resource hub envisioned in section 4.2.1, or could be a completely separate agency under the Ministry of Finance or another government ministry.

In addition to these steps to funnel outside financial support to small projects, the GOI can also take steps to provide direct financial assistance. The Indonesian national budget (APBN) currently allocates IDR 5.5 trillion for investments in new infrastructure to meet electrification goals, while over ten times that amount-IDR 66.1 trillion — is allocated to subsidize ongoing operations and consumption under PLN's public service obligation (ADB 2016). The disproportionate focus on

\footnotetext{
${ }^{8}$ According to in-country interviews with potential developers
} 
subsidizing operating costs rather than infrastructure investments favors low-capital, high-fuel-cost diesel generation over renewable technologies that often require more up-front capital but deliver far lower operating expenses. Simply flipping these subsidies to focus more on infrastructure and less on operations could encourage investment in renewable energy solutions that typically have higher up-front but lower lifetime costs compared to diesel.

\subsection{Enable Flexible, Innovative Business Models}

Rapid, widespread deployment of renewable energy in remote grids will ultimately hinge on the ability of private enterprises to make a viable business case as renewable energy suppliers.

Traditional commercial business models used by large-scale IPPs may not be applicable — or even viable_-for entities engaged in providing renewable power to small, remote communities. In many cases, electricity regulations are not designed to accommodate the needs of small enterprises or those utilizing innovative new technologies or service delivery mechanisms. The global energy landscape is changing rapidly, and for power service companies to thrive, they need an environment in which they can be flexible and adapt to shifting trends in technology as well as the evolving needs of their customers.

Additionally, variability in the local culture, social structure, population, and energy needs among many remote communities means that there will be no single perfect solution that can be replicated everywhere. As already discussed in section 4.2, close partnership with local communities is a critical step to achieving long-term success. This means that small power producers will need to find not only technology, but also business solutions, that can easily integrate into the fabric of the community, which will require an open and enabling regulatory environment.

Innovation in business models can occur both in the development phases (in terms of how a project is financed and developed) and in the operational phases (in terms of how off-take and payment are set up) of a project, and it is critical that utilities, regulators, and policymakers all be able to adapt to innovation in both. ${ }^{9}$ The range of new power service business models is growing quickly, but several have proven viable and replicable in multiple settings. A recent NREL report (Walters et al. 2015) offers a more detailed treatment of these models briefly summarized:

- Power Purchase Agreements. A PPA is one of the more recognized models by which an IPP owns and maintains the system and sells power directly to a utility, distributor, or large customer. The key aspect of a PPA is that the IPP has a guarantee that power they produce will be purchased at a certain price, reducing investor risk and providing a basis for project financing, as long as the PPA can be agreed upon prior to project development. Standardization of PPAs, so that developers and investors know in advance the kind of terms they can get, can provide certainty and facilitate investment commitments for projects.

\footnotetext{
${ }^{9}$ Many of the business models summarized operate only under the assumption of an open power market in which generators can sell power either to utilities or directly to consumers. While PLN's legal monopoly over power generation, transmission, and distribution was dissolved in 2009, its right of first refusal on activities in the power sector still allows it to exercise an effective monopoly (ADB 2015b).
} 
- Pay-As-You-Go. This model allows consumers to pre-pay for power-much as one might for mobile phone service. This replicates the cash flow of paying for kerosene up-front and allows customers to purchase power as they can afford it. This model works well in situations where a power supplier (e.g., a mini-grid operator or an energy service company) owns assets and sells power directly to consumers, typically those with lower incomes. In Indonesia this is still often an ad-hoc arrangement, but it has been proven to work well on large scale elsewhere as well.

- Business-to-Business Partnerships. These types of partnerships can be used to tap existing distribution networks and brand recognition of non-energy partner companies, such as telecommunications companies. The partnership with a recognized company can help boost customer confidence in new technology and more rapidly expand a project's customer base.

- Lease or Fee for Service. This model allows small power producers to maintain ownership of generation assets and simply lease the systems to customers or a utility, reducing the up-front cost to households. This type of model generally works better with distributed renewable assets, such as solar home systems, rather than larger micro-utility scale systems.

- Community Partnerships. This type of business model is community-based with local responsibility for at least some aspect of ownership or management of the grid, including fee collection. This model often works when reliable power for local schools, clinics, or other institutions is a high priority. In Indonesia, such an arrangement could be especially applicable for development of mini-grids in small, remote communities.

\section{Case Study 7: Mali Encourages Private-Sector Mini-grid Development}

As of the early 2000's, Mali-a country in land-locked West Africa-had little to no market for mini-grids. Yet just over a decade later, a vibrant mini-grid market had sprung up, with over 160 operating mini-grids in Mali as of 2015. Mali took an open and flexible approach to help foster this market by providing multiple avenues for mini-grid developers to engage in the market, including support for both competitive bidding of projects and spontaneous proposals. Additionally, AMADER - the Malian agency responsible for the mini-grid program-provided flexible support for a variety of business models, including provisions to allow mini-grid operators to set their own tariffs at commercially-viable rates, which has encouraged innovative business models and led to faster deployment.

\section{Reference: Walters et a. 2015}

\subsubsection{Execution Pathway for Indonesia: Support Business Models Tailored to Community Circumstances}

As most remote communities in Indonesia still rely on diesel-generated power (either through small utility gen-sets or home generators), there has been little precedent to date for exploring alternative business models outside of a few isolated projects. Still, such pioneering projects can shed valuable insight into what has worked and what can still be improved within the Indonesian context, and they can be looked to as a starting point. As ESDM aims to scale up remote renewable energy access through a targeted new rural electrification program, the opportunity is ripe to embrace multiple new business models. Initial demonstration projects (see section 4.4) can be used as a proving ground not only for new technology, but also new service delivery models. 
With a heavy emphasis on community governance and local leadership, it is all but certain that successful models in Indonesia will need to incorporate aspects of community partnerships to some degree. While it may be difficult for outside companies to dedicate the resources needed to develop the necessary level of understanding and rapport with local communities, ESDM and PLN regional offices may be well suited and poised for the task. By acting as a key catalyst between communities and small power companies, ESDM and PLN regional offices could lessen this initial barrier and help draw new and innovative energy enterprises into Indonesia's remote communities.

\section{Pathways for Executing the Strategies in Indonesia}

Chapter 4 suggested seven elements of a strategy for widespread deployment of renewable electricity in remote locations and ten tailored pathways for executing those strategic elements in Indonesia. As indicated previously, the strategic elements and execution pathways for Indonesia were not necessarily presented in sequential order, nor were they intended to be exhaustive. The sequence of steps for pursuing nationwide deployment will depend on the status of current efforts both regionally and nationally, as well as the overarching socio-political climate. The goal of this report is to identify a limited number of high-priority actions that might help lay a strong foundation for additional activities in Indonesia.

Nevertheless, executing ten pathways at once would still be a challenge for any national government, emphasizing the need for prioritization and sequencing to guide initial efforts and ensure initiatives are undertaken in a manageable way. By highlighting the linkages between execution pathways, this chapter aims to draw a complete picture of how the strategies presented in Chapter 4 might fit together to form a comprehensive suite of actions to be implemented in Indonesia-including how previous efforts under SERIG may be leveraged to accelerate those efforts. Note that the following does not represent the only possible approach for Indonesia, but rather one of several options. Ultimately, those responsible for remote electrification in Indonesia will need to formulate the most appropriate way forward for the country.

\subsection{Execution Pathways for Indonesia}

Establishing national goals and coordinating the actors responsible for implementing them is the foundation upon which any national-level strategy must be based, and Indonesia has made strides in this area by setting goals of $25 \%$ renewable energy by 2025 and near-universal electrification by 2020. Still, the work is only beginning and there are actions that can be taken to help accelerate the pace, such as strengthening coordination among relevant ministries and actors_-perhaps through an established inter-ministry task force explicitly responsible for coordination.

Provision of proof of concept at the local scale is a critical early step and can tie directly in to efforts to engage and develop stakeholders. Demonstration sites can serve as a valuable learning tool to help develop a trained workforce while bolstering faith in the ability of new technology to deliver. However, demonstration sites are only effective so long as the effort is sustained to keep them working and solve challenges as they arise, hence the critical importance of investing in highquality demonstration sites and working through problems. The three SERIG pilot sites could serve as such educational demonstration sites. 
To maximize the impact of demonstration sites, a centralized resource hub for remote renewable energy knowledge, assistance and outreach can serve as a key focal point to coordinate demonstration efforts and facilitate workshops and trainings aimed at building a workforce and educating stakeholders. Such a hub could also assist developers with relevant guidance on remote energy regulations and important procedures, and even help connect developers with appropriate sources of finance by serving as a financial intermediary.

While demonstration and stakeholder development efforts are underway, parallel efforts can be made to assess and identify opportunities for remote renewable energy development. A nationwide opportunity assessment incorporating resource, infrastructure, consumption and cost data can serve as a first pass to identify remote locations worthy of further investigation. Providing standardized guidance on feasibility studies can help ensure that those responsible for more detailed, site-specific follow-up investigations are doing a thorough and accurate job and only recommending sites that are truly bankable.

Once remote renewable energy concepts are proven, stakeholders are engaged and supportive, and the best opportunities are identified, the next step is to hand the process off to developers. Before this can be done, however, the investment climate must be right and certain regulations and safeguards must be in place. Efforts to strengthen and clarify the regulatory framework in regards to remote renewable energy, such as revising interconnection rules and domestic content requirements, can provide much-needed certainty and ease investor fears. At the same time, technology-agnostic feed-in-tariffs proportionally benchmarked to the local cost of dieselrather than to nationwide average costs of specific renewable energy technologies - can simplify the tariff structure and help selectively guide developers to those remote locations that currently operate at the highest monetary loss.

Bundling remote projects of similar scope or geography can boost economies of scale and help attract large investors who may otherwise ignore such small and remote projects. In some cases, it may be appropriate for the government to financially back remote renewable energy projects through mechanisms such as loan guarantees or by adjusting national budget priorities. Ultimately, though, widespread deployment will hinge on the ability of private enterprises and government to support innovative new business models tailored to community circumstances across the nation.

Figure 2 provides a graphical representation of the linkages between the execution pathways, as described in this section, and a possible sequence for executing these pathways in Indonesia's context. It is important to acknowledge that progress toward some of the execution pathways presented here has already started in Indonesia, jumpstarting the movement toward widespread remote renewable energy deployment. 


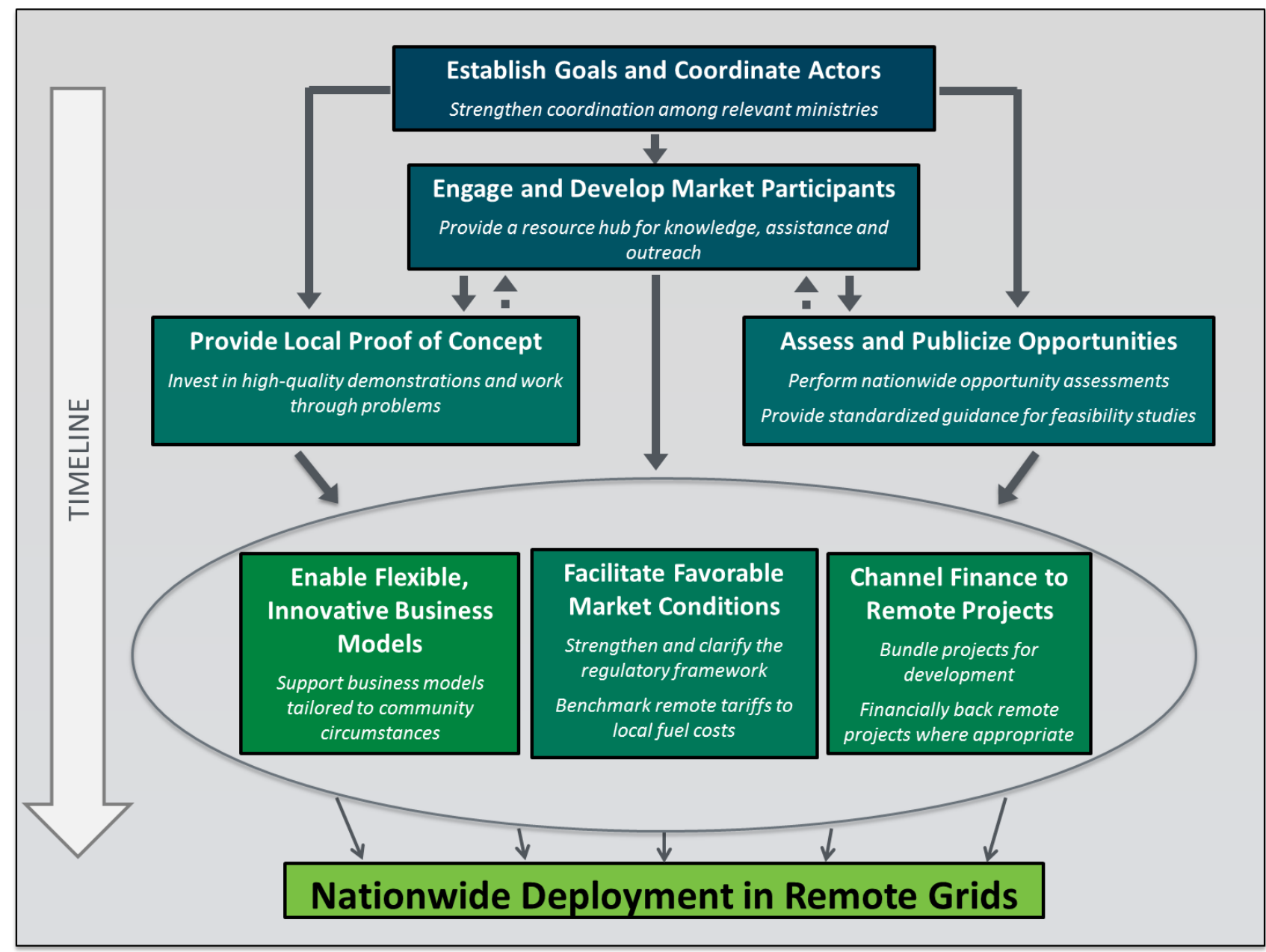

Figure 2. Linkages between the execution pathways, and a possible sequence for implementation in Indonesia.

\subsection{Leveraging Prior SERIG Work}

The prior phase of SERIG took a bottom-up approach to remote renewable energy site selection, analysis and evaluation. That work has laid significant foundations that can serve as a starting point for many of the strategies presented here and help accelerate their implementation in Indonesia.

The coarse regional screening methodology applied in the prior SERIG analysis could be used as a basis for performing further nationwide opportunity assessments. Further, SERIG has already performed a rough screening of 200 potential sites -3 of which were selected for more detailed feasibility studies, but 197 of which still represent high priorities ready for further analysis. Going a step further, the more detailed techno-economic analyses and pre-feasibility studies performed on the three SERIG sites at Lamandau, Sabu, and Sumba could be used as a basis for developing standardized guidance for later-stage, site-specific feasibility studies.

If adopted, the SERIG methodologies — both for coarse nationwide screening and more detailed, sitespecific feasibility analyses - could also serve as starting components for a renewable energy 
resource hub. Technical trainings and workshops on these important topics could be an initial offering of the hub in its early development stages and help draw support for additional trainings on other relevant aspects of remote renewable energy development.

With the pre-feasibility studies done and an interested network of local stakeholders at the ready, the three sites at Lamandau, Sabu, and Sumba are primed for development and could serve as valuable demonstration sites to provide much-needed local proof of concept. With three different technologies (solar PV, biogas from POME, and wind), the sites taken together could serve to demonstrate a suite of hybrid renewable energy options and serve as living laboratories and teaching sites if coupled with an Indonesian clean energy resource hub.

Figure 3 is an expanded version of Figure 1 that illustrates where and how earlier work under the SERIG project might serve as a starting point for, and feed into, aspects of the strategies for accelerating nationwide deployment presented in this report.

\begin{tabular}{|c|c|c|}
\hline Strategic Elements & Execution Pathways for Indonesia & Leveraging Prior SERIG Work \\
\hline $\begin{array}{l}\text { Establish Goals and } \\
\text { Coordinate Actors }\end{array}$ & $\begin{array}{l}\text { - Strengthen coordination among relevant ministries } \\
\text { and task forces }\end{array}$ & \\
\hline $\begin{array}{l}\text { Engage and Develop } \\
\text { Market Participants }\end{array}$ & $\begin{array}{l}\text { - Provide a resource hub for knowledge, assistance } \\
\text { and outreach }\end{array}$ & $\begin{array}{l}\text { - Incorporate SERIG techniques into hub } \\
\text { - SERIG pilots serve as remote living laboratories }\end{array}$ \\
\hline $\begin{array}{l}\text { Assess and Publicize } \\
\text { Opportunities }\end{array}$ & $\begin{array}{l}\text { - Perform nationwide opportunity assessments } \\
\text { - Provide standardized guidance for feasibility studies }\end{array}$ & $\begin{array}{l}\text { - } 200 \text { sites pre-screened for further assessment } \\
\text { - SERIG analyses inform feasibility study guidance }\end{array}$ \\
\hline $\begin{array}{l}\text { Provide Local Proof of } \\
\text { Concept }\end{array}$ & $\begin{array}{l}\text { - Invest in a few, high-quality demonstrations and } \\
\text { work through problems }\end{array}$ & $\begin{array}{l}\text { - Pilot sites at Lamandau, Sabu and Sumba } \\
\text { primed for development as demonstrations }\end{array}$ \\
\hline $\begin{array}{l}\text { Facilitate Favorable } \\
\text { Market Conditions for } \\
\text { Renewables }\end{array}$ & $\begin{array}{l}\text { - Strengthen and clarify the regulatory framework } \\
\text { - Benchmark remote tariffs to local fuel costs }\end{array}$ & \\
\hline $\begin{array}{l}\text { Channel Finance to } \\
\text { Remote Projects }\end{array}$ & $\begin{array}{l}\text { - Bundle projects for development } \\
\text { - Financially back remote projects where appropriate }\end{array}$ & \\
\hline $\begin{array}{c}\text { Enable Flexible, } \\
\text { Innovative Business } \\
\text { Models }\end{array}$ & $\begin{array}{l}\text { - Support business models tailored to community } \\
\text { circumstances }\end{array}$ & \\
\hline
\end{tabular}

Figure 3. Prior work under the SERIG project can serve as a starting point for some execution pathways and feed directly into implementation of the strategies. Note that previous work under SERIG offers only a starting point and may not necessarily contribute to all seven of the strategic elements.

\subsection{Moving Forward}

The Government of Indonesia has made substantial commitments to clean energy, ranging from ambitious goal setting to concrete efforts to reduce fossil fuel consumption and finance new and renewable energy projects in targeted regions. Further, providing electricity to the approximately $15 \%$ of the population still without access remains a national goal that will require increased funding and institutional and technical innovation, including widespread renewable energy deployment in remote locations. Mass deployment on the scale that these tasks require can be challenging due to 
Indonesia's diversity, unique cultural heritage, and institutional intricacies. However, many other nations and regions have confronted similar challenges and are successfully expanding clean energy initiatives.

Drawing upon prior in-country experience, discussions with key public and private Indonesian stakeholders, lessons from other nations, and NREL's wealth of international experience, the strategies presented here provide a framework for accelerating widespread renewable energy deployment in remote grids. Further, pathways for executing the strategies in Indonesia, based upon the nation's current progress and efforts, have been suggested that could help expand renewable energy use and increase access to electricity across the nation's hundreds of isolated grids.

These strategies alone, however, will not induce change. Only committed and resolute action will transform the concepts here into tangible new energy infrastructure that will bring clean, reliable power to all of Indonesia's 250 million people and meet the nation's ambitious - yet achievablegoals. With such a vast diversity of resources and a wealth of human capacity at hand, Indonesia is poised to take its place as one of the world's foremost clean energy leaders. 


\section{References}

Asian Development Bank (ADB). 2015a. "Tariff Support for Wind Power and Rooftop Solar PV in Indonesia”, March 2015. http://static1.squarespace.com/static/53bcdf41e4b0dcd494de635e/t/553f018fe4b0a46bddb2d6b8/143 0192527324/CAT+Projects+Indonesia+Wind++RooftopPV+tariffs.pdf

Asian Development Bank (ADB). 2015b. "Summary of Indonesia's Energy Sector Assessment." December 2015. https://www.adb.org/sites/default/files/publication/178039/ino-paper-09-2015.pdf

Asian Development Bank (ADB). 2016. "Achieving Universal Electricity Access in Indonesia", 2016. https://www.adb.org/sites/default/files/publication/182314/achieving-electricity-accessino.pdf

Castle \& Cooke. 2012. "Lanai Solar Farm Generating 1.5MW." The Molokai Dispatch, April 27, 2012. https://themolokaidispatch.com/lanai-solar-farm-generating-1-5-mw/

Energy Storage Association. 2016. "Solar PV-Storage: Lanai Sustainability Research Dynamic Power Resource (DPR) Energy Storage.” Accessed October 17, 2016. http://energystorage.org/energy-storage/case-studies/solar-pv-storage-lanai-sustainability-researchdynamic-power-resource

Fu, R., Chung, D., Lowder, T., Feldman, D., Ardani, K., and Margolis, R. 2016. "U.S. Solar Photovoltaic System Cost Benchmark: Q1 2016, NREL/TP-6A20-66532, September 2016. http://www.nrel.gov/docs/fy16osti/66532.pdf

Gahran, Amy. 2015. "Utility-scale solar in Hawaii, batteries included." Greentech Media, September 15, 2015. http://www.greentechmedia.com/articles/read/Utility-Scale-Solar-In-Hawaii-BatteriesIncluded

Hawaii Clean Energy Initiative. 2016. "Hawaii is the Most Fossil Fuel Dependent State in the Nation", 2016. http://www.hawaiicleanenergyinitiative.org/

Hirsch,B., Burman, K., Davidson, C., Elchinger, M., Hardison, R., Krsiwulan, D., and Castermans, B. 2015. "Sustainable Energy for Remote Indonesian Grids: Accelerating Project Development", NREL/TP-7A40-64018, June 2015. http://www.nrel.gov/docs/fy15osti/64018.pdf

International Institute for Sustainable Development (IISD) and the Global Subsidies Initiative (GSI). 2015. "Indonesia Energy Subsidy Briefing." November 2015.

https://www.iisd.org/gsi/sites/default/files/ffs indonesia_newsbriefing_Nov2015 eng.pdf

International Institute for Sustainable Development (IISD) and the Global Subsidies Initiative (GSI). 2016. Financing Development with Fossil Fuel Subsidies: The reallocation of Indonesia's gasoline and diesel subsidies in 2015. May 2016.

http://www.iisd.org/sites/default/files/publications/financing-development-with-fossil-fuel-subsidiesindonesia.pdf 
Ministry of Energy and Mineral Resources (ESDM), Republic of Indonesia. 2014. "Handbook of Energy \& Economic Statistics of Indonesia", November 2014.

http://prokum.esdm.go.id/Publikasi/Handbook\%20of\%20Energy\%20\&\%20Economic\%20Statistics \%20of\%20Indonesia\%20/HEESI\%202014.pdf

Ministry of Energy and Mineral Resources (ESDM). 2015. "Roadmap for Accelerated Development of New and Renewable Energy." Indonesia, Jakarta, May 2015. http://nusantarainitiative.com/wpcontent/uploads/2015/08/Road-Map-EBTKE-2015-2025.pdf

Oswal, R., Jain, P., Muljadi, E., Hirsch, B., Castermans, B., Chandra, J., Raharjo, S., and Hardison, R. 2016. "System Impact Study of Eastern Grid of Sumba Island, Indonesia", NREL/TP-5D0065458, January 2016. http://www.nrel.gov/docs/fy16osti/65458.pdf

U. S. Department of Energy (DOE), Office of Energy Efficiency and Renewable Energy (EERE). "Energy Transistion Initiative: Islands Playbook". http://www.eere.energy.gov/islandsplaybook/pdfs/islands-playbook.pdf.

U.S. Department of Energy (DOE), Office of Energy Efficiency and Renewable Energy (EERE). 2014. "EERE Success Story—Enhanced Efficiency of Wind-Diesel Power Generation in Tribal Villages." June 17, 2014. http://energy.gov/eere/success-stories/articles/eere-success-storyenhanced-efficiency-wind-diesel-power-generation

U.S. Department of Interior (DOI), Office of Insular Affairs (OIA). 2016. "OIA/NREL Territorial Energy Program.” Accessed October 18, 2016. https://www.doi.gov/oia/reports/OIANRELTerritorialEnergy

Waldholz, Rachel. 2016. "At the mouth of the Kusko, a pioneering wind system." Alaska Public Media. February 25, 2016. http://www.alaskapublic.org/2016/02/25/at-the-mouth-of-the-kusko-apioneering-wind-system/

Walters, T, Esterly, S., Cox, S., Reber,T., and Rai, N. 2015. "Policies to spur Energy Access: Volume 1, Engaging the Private Sector in Expanding Accesss to Electricity", NREL/TP-7A4064460, September 2015. http://www.nrel.gov/docs/fy15osti/64460-1.pdf

Winrock International. 2010. "Fuel Independent Renewable Energy, Iconic Island”, August 2010. https://hivos.org/sites/default/files/islands_assessment_report__wi_for_hivos_august_2010.pdf

Winrock International. 2015. "Handbook, POME-to-Biogas, Project Development in Indonesia", 2015. https://www.winrock.org/wp-content/uploads/2016/05/CIRCLE-Handbook-2nd-Edition-EN25-Aug-2015-MASTER-rev02-final-new02-edited.pdf

World Wide Fund (WWF). 2013. "Meeting Renewable Energy Targets: Global lessons from the road to implementation”, 2013. http://awsassets.panda.org/downloads/meeting_renewable_energy targets_low_res_.pdf 